\title{
Salario mínimo y distribución salarial: evidencia para Argentina $2003-2013$
}

\author{
Malena Arcidiácono
}

\author{
Tesis de Maestría \\ Maestría en Economía \\ Universidad Nacional de La Plata \\ Director: Roxana Maurizio \\ Co-director: Mariana Marchionni
}

19 de Mayo de 2015 


\title{
Salario mínimo y distribución salarial: \\ evidencia para Argentina $2003-2013^{*}$
}

\author{
Malena Arcidiácono ${ }^{\dagger}$
}

\begin{abstract}
Resumen
En el presente trabajo se estudia el impacto distributivo del aumento del salario mínimo evidenciado en Argentina durante el período 2003 - 2013. Utilizando información de la Encuesta Permanente de Hogares Continua, se estima mediante el método propuesto por Lee (1999) el efecto casual del salario mínimo sobre la distribución salarial de los asalariados a tiempo completo. Los resultados sugieren un efecto igualador del aumento del salario mínimo real para el total de asalariados y para los asalariados formales, no así para los asalariados no registrados. Al descomponer la caída observada de la desigualdad salarial entre la variación aportada por el aumento del salario mínimo real y aquella relacionada con otros factores, el aumento del valor del salario mínimo explica una disminución de las brechas salariales, entre en promedio, de 0.5 p.p. por año, para los trabajadores formales, y de 0.3 p.p. para el total de asalariados.
\end{abstract}

Código JEL: D31, J31, J38, 015, 017

Palabras clave: Distribución del ingreso, Desigualdad, Salario mínimo, Argentina.

\footnotetext{
* Agradezco a Roxana Maurizio y Mariana Marchionni por el apoyo, el aliento y la dirección a lo largo de este proceso; a los asistentes del seminario de avances por sus comentarios; y finalmente a Darío Tortarolo por su apoyo, sus sugerencias y reiteradas lecturas de la tesis. Los errores u omisiones son de mi entera responsabilidad.

+ Centro de Estudios Distributivos, Laborales y Sociales, Facultad de Ciencias Económicas, Universidad Nacional de La Plata. Email: marcidiacono@cedlas.org
} 


\section{Índice}

$\begin{array}{ll}\text { 1. Introducción } & 2\end{array}$

2. Enfoques teóricos y revisión de la literatura empírica 4

2.1 Salario mínimo y empleo $\quad 4$

2.2 Salario mínimo y desigualdad salarial. Evidencia empírica internacional 6

3. Aspectos institucionales del salario mínimo 9

$\begin{array}{ll}\text { 4. Fuente de datos } & 12\end{array}$

$\begin{array}{ll}\text { 5. Metodología } & 14\end{array}$

$\begin{array}{ll}\text { 6. Salario mínimo y desigualdad salarial: algunas estadísticas descriptivas } & 18\end{array}$

6.1 Salario mínimo, índice de precios y estructura de las remuneraciones 19

6.2 Alcance del salario mínimo 22

6.3 Evolución de la desigualdad 26

$\begin{array}{ll}\text { 7. Resultados } & 30\end{array}$

$\begin{array}{ll}7.1 \text { Efecto del salario mínimo } & 30\end{array}$

7.2 Descomposición del cambio en la desigualdad salarial: la contribución del salario mínimo 34

$\begin{array}{ll}\text { 8. Comentarios finales } & 37\end{array}$

$\begin{array}{ll}\text { 9. Referencias } & 37\end{array}$

$\begin{array}{ll}\text { A. Apéndice } & 42\end{array}$ 


\section{Introducción}

La primera década de 2000 significó para Argentina un marcado cambio en las condiciones económicas del país respecto a los años anteriores. El comienzo del nuevo siglo estuvo acompañado por una disminución significativa de la desigualdad de ingresos y un fortalecimiento de las instituciones laborales.

Desde el año 2003 y como consecuencia del efecto adverso que la crisis macroeconómica de 20012002 significó en los ingresos de los trabajadores comenzó una etapa caracterizada por políticas laborales más fuertes, que dio origen a una actualización del salario mínimo en 2003, luego de 10 años de permanecer constante en términos nominales. Los importantes ajustes del valor nominal del salario mínimo desde 2003 hasta la actualidad hicieron que dicha institución se convierta nuevamente en una política efectiva para la fijación de los salarios, al menos hasta el año 2007, momento en el que el aumento sostenido de la inflación puso un freno a la recuperación del valor real del salario mínimo ${ }^{1}$.

La recuperación del valor nominal del salario mínimo estuvo acompañada por una reducción en la dispersión de ingresos. Las mejoras distributivas observadas a partir de 2003 contrastan fuertemente con la tendencia creciente en la desigualdad de ingresos que experimentó Argentina desde los años 1970 hasta alcanzar su punto máximo con la crisis de 2001-2002 ${ }^{2}$. Diversos fueron los factores que se combinaron para generar un escenario de reducción en la desigualdad: la recuperación de la crisis del 2001-2002, el cambio en los precios relativos de los commodities, una fuerte expansión del empleo, cambios productivos inducidos por los nuevos precios relativos a favor de los sectores intensivos en mano de obra de baja calificación, instituciones y políticas laborales más fuertes, y un conjunto de redes de protección más amplias caracterizada por una expansión de la cobertura de programas de transferencias monetarias (Gasparini y Cruces, 2008; Gasparini, Cruces, Tornarolli y Marchionni, 2009; López Calva y Lustig, 2010; Gasparini, Cruces y Tornarolli, 2011; Gasparini y Lustig, 2011; Beccaria y Maurizio, 2012; Cornia, 2012; Cruces y Gasparini, 2013; Alvaredo y Gasparini, 2013).

Si bien este cambio en la trayectoria de la desigualdad desde comienzos de 2000 ha sido objeto de estudio de varios trabajos que contribuyeron a la documentación de la evolución de la dispersión de ingresos, la evidencia empírica que trata de medir el efecto de los distintos factores es aún escasa. La misma se ha centrado principalmente en dos factores: i) en los programas de transferencias condicionadas, entre los cuales resultan importante el Programa Jefes y Jefas de

\footnotetext{
${ }^{1}$ Para un mayor análisis del salario mínimo en la década de 1990 véase Beccaria y Gain (2003) y Marinakis y Velasco (2006), estos últimos extienden el análisis hasta la primera mitad de los años 2000.

${ }^{2}$ Altimir, Beccaria y González Rozada (2002) realizan un análisis de la evolución de la desigualdad y el efecto de los cambios laborales sobre la misma para el período 1974-2000. Por su parte, Gasparini y Cruces (2008) estudian la evolución de la desigualdad desde los años '70 hasta mediados de 2000, y presentan un conjunto de factores capaces de determinando la evolución de la misma. En la misma línea, Beccaria y Maurizio (2012) analizan los regímenes macroeconómicos y la evolución de la desigualdad desde comienzos de los años '90.
} 
Hogar Desempleados y la Asignación Universal por Hijo (Maurizio, 2008; Bertranou y Maurizio, 2011; Alejo, Bérgolo y Carbajal, 2013; Azevedo, Inchauste y Sanfelice, 2013; Cruces y Gasparini, 2013; Lustig, Lopez-Calva y Ortiz-Juarez, 2013) y ii) en el rol de la educación (Gasparini, Galiani, Cruces y Acosta, 2011; Alejo, 2012; Azevedo, Dávalos, Diaz-Bonilla, Atuesta y Castañeda, 2013; Lustig et al., 2013; Beccaria, Maurizio y Vazquez, 2014; Battistón, García-Domench, y Gasparini, 2014).

Otros de los factores estudiados, aunque en menor medida, son: la mejora en la cobertura de la Seguridad Social (Bertranou y Maurizio, 2011; Keifman y Maurizio, 2012; Alejo et al., 2013); los cambios en la estructura de producción (Gasparini et al., 2011b); la calidad de la educación, la experiencia de los trabajadores (Azevedo et al., 2013b); los cambios en la formalización laboral (Bertranou y Maurizio, 2011; Keifman y Maurizio, 2012; Beccaria et al., 2014; Maurizio, 2014b); los cambios en los retornos y en la estructura de las características de los trabajadores relacionadas con la edad, género y rama de actividad (Beccaria et al., 2014); y el efecto del aumento del salario mínimo (Keifman y Maurizio, 2012; Maurizio, 2014a).

Al dividir la disminución en la dispersión de ingresos de acuerdo a mejoras distributivas de los ingresos laborales y de los no laborales, la evidencia es concluyente en cuanto a la mayor importancia de los ingresos laborales en la caída de la desigualdad (Bertranou y Maurizio, 2011; Trujillo y Villafañe, 2011; Keifman y Maurizio, 2012; Alejo et al. 2013; Azevedo et al., 2013a). En este sentido, Alejo et al. (2013) sostienen que "el cambio en la distribución marginal del ingreso laboral fue la principal fuerza que afectó la dinámica de la desigualdad en la década de 2000 ". Los autores encuentran que entre 2001 y 2009, 4.7 puntos porcentuales de la caída del índice de Gini se debe a mejoras distributivas en el ingreso laboral. Por su parte, Trujillo y Villafañe (2011) encuentran que la mejora distributiva experimentada entre 2004 y 2008 se debe casi en un $90 \%$ a la mejora distributiva de los ingresos laborales.

En este contexto, el objetivo del presente trabajo en identificar si la política de salario mínimo ha favorecido, y en qué medida, a la reducción de la dispersión salarial en Argentina entre 2003 y 2013. La relevancia del trabajo radica en aportar evidencia adicional a la escasa literatura existente sobre los efectos del salario mínimo en la distribución salarial en Argentina, mediante la utilización de un método estimación alternativo, el método propuesto por Lee (1999). A su vez, el trabajo realiza un aporte en cuanto al universo de análisis. Las estimaciones se realizan tanto para el total de asalariados, así como para grupo de asalariado según su condición de formalidad, esto es, asalariados registrados y no registrados en la seguridad social.

Es necesario comentar que en el presente trabajo no se consideran los posibles efectos del salario mínimo sobre la demanda de empleo. Si bien existe gran controversia en cuanto a los efectos que la imposición de un salario mínimo puede tener sobre el nivel de empleo, a la vez que la evidencia empírica no es concluyente, Groisman (2012) no encuentra evidencia a de efectos adversos sobre el empleo producto del incremento del valor del salario mínimo para el caso de Argentina durante la primera década de 2000. 
Los resultados obtenidos del análisis de las tendencias de las brechas de salariales de los distintos percentiles del ingreso respecto al ingreso mediano sugieren una disminución de las mismas a lo largo del período analizado, en mayor medida en la cola superior de la distribución, tanto para el total de asalariados como para los asalariados formales.

Adicionalmente la estimación del impacto del salario mínimo revela un efecto igualador a lo largo de casi toda la distribución salarial, especialmente fuerte en la cola inferior de la distribución de los asalariados formales. Mientras que el aumento del valor del salario mínimo explica una caída, en promedio, de 0.5 p.p. por año, para los trabajadores formales, para el total de asalariados es de 0.3 p.p.; ambas estadísticamente significativas.

El resto del trabajo se estructura de la siguiente manera. En la sección 2 se realiza una revisión de enfoques teóricos así como de literatura relacionada al efecto del salario mínimo sobre el mercado de trabajo. La sección 3 se dedica a los aspectos institucionales del salario mínimo y a la evolución nominal del salario mínimo en Argentina desde comienzos de 2003. En la sección 4 se detalla la fuente de información utilizada así como el universo de análisis, mientras que el método de estimación utilizado para evaluar el efecto del salario mínimo sobre la distribución de salarios se describe en la sección 5 . En la sección 6 se presentan una serie de estadísticas descriptivas, para luego discutir los resultados de las estimaciones en la sección 7. La sección 8 concluye con algunos comentarios finales.

\section{Enfoques teóricos y revisión de la literatura empírica}

\subsection{Salario mínimo y empleo}

La implementación de un salario mínimo tiene como objeto establecer un piso salarial para las remuneraciones de los asalariados, protegiendo de esta manera a la población de menores ingresos. Sin embargo, los efectos que la implementación del salario mínimo puede tener sobre el nivel de empleo representa uno de los aspectos más controversiales al estudiar políticas de salario mínimo. Bajo la hipótesis de efecto censura del salario mínimo sobre la distribución salarial, aquellos asalariados que ante la ausencia del salario mínimo recibirían una remuneración menor al mismo, se concentran en el entorno del salario mínimo una vez implementado. En este escenario el salario mínimo cumpliría su función de umbral de las remuneraciones, a la vez que no se evidenciarían efectos negativos sobre el empleo. Sin embargo, si en lugar de censurar la distribución la fijación de un salario mínimo tiene un efecto truncamiento, la implementación del salario mínimo podría dejar sin empleo a aquellos trabajadores con ingresos inferiores al mínimo. Bajo la hipótesis de "truncamiento", la introducción de un salario mínimo afectaría negativamente el empleo.

La falta de consenso del efecto del salario mínimo sobre el nivel de empleo es tanto empírica como conceptual. Por el lado teórico, en los modelos de competencia perfecta, la instauración de un salario mínimo por encima del salario de equilibrio tendrá un efecto negativo sobre el empleo, 
en particular sobre aquellos individuos para los cuales el salario mínimo resulta operativo. Este efecto será mayor, cuanto mayor sea la elasticidad precio de la demanda.

En discrepancia con el modelo clásico de funcionamiento del mercado laboral, los modelos de mercados monopsónicos postulan que el salario de equilibrio se encuentra por debajo del valor de la productividad marginal del trabajo, por lo que, el efecto sobre el empleo de un aumento de las remuneraciones a través de la fijación de un salario mínimo es indeterminado. Disminuciones, incrementos en el nivel de empleo, o la ausencia de variación en el mismo dependerá en última instancia de la elasticidad de las curvas del valor de la productividad marginal del trabajo, del costo marginal de producción y de la curva de oferta de trabajo (Manning, 2003). En la teoría de salarios de eficiencia los efectos sobre el empleo de la fijación de un salario mínimo son también indeterminados. Si aumentos salariales producto de la instauración del salario mínimo incrementan la productividad del trabajo, no se observaría una disminución del empleo (Akerlof y Yellen, 1990).

La falta de acuerdo sobre los efectos del salario mínimo sobre el empleo no se limita solamente a los modelos teóricos. La evidencia empírica en cuanto a este efecto tampoco es concluyente. Mientras que algunos autores sostienen que aumentos en el salario mínimo conllevan incrementos en el desempleo, otros enfatizan que los efectos sobre el empleo son nulos, o en caso de ser negativos, de escasa significatividad económica. Los trabajos que apoyan la creencia convencional del efecto negativo del salario mínimo sobre el empleo corresponden a investigaciones llevadas a cabo para Estados Unidos para la década de 1980 (Brown, Gilroy, y Kohen, 1982; Kim y Taylor, 1995; Neumark y Wascher, 1995), así como para Europa (Abowd, Kramarz y Margolis, 1999; Dolado et al., 1996). Una década más tarde, distintos autores pusieron en duda los resultados antes encontrados. Los nuevos estudios concluyeron que aumentos en el salario mínimo no tienen efecto en el nivel empleo, o en caso de existir alguna disminución en el mismo es de baja significatividad económica (Card, 1992; Katz y Krueger, 1992; Card y Krueger, 1994; Machin y Manning, 1994; Bernstein y Schmitt, 1998; Dickens, Machin y Manning, 1999; Holmlund, 2013).

Al investigar los efectos del salario mínimo sobre el empleo en los países en desarrollo debe tenerse en cuenta que un hecho característico de los mismos es que cuentan con una alta tasa de informalidad. Esta característica propia de las economías en desarrollo podría implicar que, ante aumentos en el salario mínimo, individuos que antes estaban empleados en el sector formal queden desempleados, aumentando la oferta de empleo en el sector informal y por lo tanto disminuyendo las remuneraciones de los asalariados informales (Betcherman, 2014). Sin embargo, el mismo autor sostiene que aunque la mayoría de las investigaciones llevadas a cabo en países en desarrollo encuentren algunos efectos negativos sobre el empleo, dichos efectos son a menudo de escasa significatividad económica. Entre los estudios que encuentran efectos negativos del salario mínimo sobre el empleo se encuentran los de Dickens, Machin y Manning (1999) para el Reino Unido, Fajnzylber (2001) para Brasil, Gindling y Terrell (2005) para Costa Rica, Gindling y Terrel (2007) para Honduras, Alaniz, Gindling y Terrell (2011) para Nicaragua, y Grau y Landerretche (2011) y Miranda (2013) para Chile. Entre las investigaciones que no encuentran evidencia a favor 
del efecto negativo del salario mínimo sobre el empleo se encuentran los trabajos de Lemos (2009) y Bosch y González-Velosa (2013) para Brasil, y Gindling, Mossaad y Trejos (2013) para Costa Rica.

Para el caso de Argentina, la evidencia es aún escasa. El trabajo de Groisman (2012) es el primero que trata de dar cuenta de los posibles cambios en el nivel de empleo como consecuencia de los incrementos en el valor nominal del salario mínimo durante la última década. Utilizando paneles anuales de la Encuesta Permanente de Hogares, evalúa los efectos de los sucesivos cambios en el salario mínimo sobre el empleo entre 2003 y 2010 a través de modelos de regresión logística multinomial. En particular, el autor estima si los asalariados con ingresos iguales o menores al salario mínimo presentaron mayor probabilidad de perder el empleo o de pasar a ser asalariados informales, esto último para los asalariados registrados. Los resultados encontrados no aportan evidencia a favor del efecto negativo del salario mínimo sobre el empleo, así como tampoco de incrementos en la informalidad laboral.

\subsection{Salario mínimo y desigualdad salarial. Evidencia empírica internacional}

Al analizar los impactos distributivos del salario mínimo distintos factores entran en juego. El primero de ellos, y comentado anteriormente, es la existencia o no de efectos negativos sobre el empleo. Si se considera la posibilidad de que el salario mínimo conlleve una disminución en el nivel de empleo, efecto truncamiento, esto podría implicar una caída de la desigualdad salarial dada la pérdida de empleo de baja remuneración, aún cuando no sean éstos los mecanismos por los cuales se pretende impactar positivamente sobre la dispersión salarial. Si en cambio lo que se observa es un efecto censura se producirá una comprensión salarial, mejorando los ingresos de los individuos más vulnerables y disminuyendo de esta manera la desigualdad.

Un caso más general del efecto censura se da cuando el salario mínimo funciona como numerario. En este escenario el salario mínimo produce una censura en los ingresos de los individuos más desfavorecidos a la vez que su impacto se extiende a lo largo de la distribución salarial. En este caso, la desigualdad salarial disminuye como consecuencia de la implementación del salario mínimo siempre que los aumentos salariales para mayores ingresos se dan a una tasa decreciente.

Por otro lado, los impactos distributivos del salario mínimo dependerán de si cambios en el valor del mismo afectan sólo a los asalariados formales o si también tiene algún impacto sobre las remuneraciones de los asalariados informales, efecto faro. En sentido estricto, la institución del salario mínimo debería afectar sólo a las remuneraciones de los asalariados formales. Bajo este supuesto, y en un escenario donde existen tanto asalariados formales e informales, el resultado sobre la desigualdad salarial total es, a priori, ambiguo. Cambios en el salario mínimo generará una disminución de la desigualdad salarial de los formales, a la vez que podría aumentar la brecha salarial entre los asalariados formales e informales. Si en cambio, la fijación de un salario mínimo sirve como referencia para las remuneraciones de los asalariados informales, podría evidenciarse una disminución de la desigualdad salarial total dado que son los trabajadores informales los que se encuentran generalmente en la cola inferior de la distribución. 
Brown (1999) sostiene que la evidencia empírica parecería ser concluyente en cuanto a los efectos positivos del salario mínimo sobre la mejora en la distribución salarial.

DiNardo, Fortin y Lemieux (1996) fueron unos de los primeros autores en estudiar el impacto distributivo del salario mínimo, y lo hicieron para Estados Unidos, para el período 1979-1988, caracterizado por un aumento de la desigualdad salarial y una disminución en el valor real del salario mínimo. Mediante un enfoque semi-paramétrico en el que simulan cómo hubiese sido la distribución salarial en el año 1988 si el salario real hubiese sido el de 1979, encuentran que la caída en el valor real del salario mínimo así como la menor tasa de sindicalización durante dicho período explican en gran parte el aumento de la desigualdad salarial en la cola inferior de la distribución. En un estudio posterior, Fortin y Lemieux (1997), utilizando un método de estimación diferente, argumentan que los cambios institucionales llevados a cabo en la década de 1980 en Estados Unidos, entre ellos la disminución del valor real del salario mínimo, explican alrededor de un tercio del aumento en la desigualdad salarial.

Lee (1999) se focaliza sobre el mismo período en Estados Unidos, y arriba a conclusiones similares utilizando un enfoque metodológico diferente. El autor encuentra que la reducción del salario mínimo entre 1979 y 1988 explica más de la mitad del aumento en la desigualdad entre los percentiles 10-50 en dicho período. Autor, Manning y Smith (2010) hacen algunas correcciones al método de Lee (1999) y llegan a resultados similares, aunque de menor magnitud, también para Estados Unidos para el período 1979-1988. Los autores sostienen que la reducción del valor real del salario mínimo explica entre un $35 \%-55 \%$ del aumento en la desigualdad salarial de las mujeres.

Machin y Manning (1994) estudian el impacto del salario mínimo sobre la dispersión salarial en el Reino Unido para la década de 1980 y encuentran que la disminución del valor del salario mínimo en relación a los niveles de salario promedio de la economía contribuyó a ampliar la dispersión salarial en esos años. Dickens et al. (1999) también centran su trabajo en el mercado laboral de Reino Unido, pero para el período comprendido entre 1975 y 1992, utilizando un modelo según el cual los empleadores tienen cierto grado de poder de monopsonio. Encuentran que la recuperación del salario mínimo durante dicho período tuvo un efecto positivo sobre la desigualdad salarial. En un trabajo posterior, también para el caso de Reino Unido, Dickens y Manning (2004) estudian cual es el impacto del Salario Mínimo Nacional, introducido en 1999, sobre la distribución del ingreso, encontrando un efecto positivo sobre la desigualdad, aunque modesto.

A diferencia de los países desarrollados, donde la evidencia pareciera ser concluyente en cuanto al efecto igualador del salario mínimo, en América Latina las investigaciones son relativamente más escasas.

Uno de los primeros trabajos que trata de dar cuenta del efecto del salario mínimo en la desigualdad salarial en los países de América Latina es el de Neri, Gonzaga y Camargo (2000) para 
Brasil. Los resultados sugieren que el salario mínimo censura la distribución salarial de los asalariados formales, de modo que beneficia a los individuos formales de menores ingresos, a la vez que es utilizado como numerario en la determinación salarial del resto de los formales. A su vez, los autores encuentran evidencia a favor del efecto faro, un gran porcentaje de los asalariados no registrados reciben el salario mínimo. En igual sentido, Fajnzylber (2001) encuentra un efecto igualar del salario mínimo con efectos derrame sobre los percentiles más altos de la distribución, tanto en sector formal como en el informal, para el período comprendido entre 1982 y 1997. Lemos (2009), usando datos de panel para el período 1982 - 2000, llega a conclusiones similares.

En un estudio más reciente, también para Brasil, Bosch y González-Velosa (2013) evalúan el impacto sobre la distribución salarial del aumento en el valor real del salario mínimo observado entre 1996 y 2010. Al igual que los estudios anteriores, encuentran evidencia a favor de un efecto significativo del salario mínimo en toda la distribución salarial, aunque desigualador en la cola inferior de la distribución que desaparece al restringir en análisis a los asalariados registrados.

Gindling y Terrel (2007) utilizando datos de Honduras para el período 1990-2004 evalúan cuales son los efectos que cambios en el salario mínimo tuvieron sobre la distribución salarial en los distintos sectores de la economía. Los autores sostienen que incrementos en el salario mínimo se corresponden con aumentos en los salarios medios.

Bosch y Manacorda (2010) siguiendo el mismo método de estimación que Lee (1999) y Autor et al. (2010) estudian la relación entre el aumento de desigualdad salarial que experimentó México entre 1989 y 2001, y la caída del salario mínimo real observado en el mismo período. Los autores encuentran que una parte sustancial del aumento de la desigualdad, en particular en la cola inferior de la distribución, se debe a la disminución del valor real que sufrió el salario mínimo en ese período.

Grau y Landerretche (2011) usando datos de panel del período 1996-2005 para Chile analizan los efectos de corto plazo del aumento del salario mínimo durante dicho período. Encuentran un impacto significativo de los incrementos del salario mínimo sobre las remuneraciones de los trabajadores con ingresos que se ubican en el valor del salario mínimo ex antes y ex post (grupo tratado).

Alaniz et al. (2011) estudian lo acontecido para Nicaragua durante el período de 1998 y 2006. Los autores sostienen que los aumentos en el salario mínimo se corresponden con incrementos salariales de los trabajadores formales que inicialmente se encontraban en el entorno del salario mínimo.

Amarante, Colafranceschi y Vigorito (2011) centran su investigación en la evolución de la desigualdad en Uruguay para el período 1981-2010, y encuentran que el aumento de la desigualdad evidenciada en la última década fue impulsada por un conjunto de factores, entre ellos, la caída del salario mínimo.

Gindling et al. (2013), a través de un enfoque de regresiones discontinuas, estudian los cambios en 
la distribución salarial de Costa Rica a partir de agosto de 2010, momento en el cual se implementó un programa para aumentar el cumplimiento de los salarios mínimos legales. Los autores encuentran evidencia a favor de un mejoramiento en la distribución salarial, en mayor medida en los salarios promedio de las mujeres, los trabajadores jóvenes y los trabajadores con menor nivel educativo.

En un estudio más general sobre el comportamiento del mercado de trabajo y la desigualdad en América Latina para la última década, Keifman y Maurizio (2012) encuentran evidencia a favor de un efecto positivo del salario mínimo sobre la distribución salarial en Argentina, Brasil y Uruguay. En un trabajo posterior, Maurizio (2014a), utilizando el método de estimación semi-paramétrico propuesto por DiNardo et al. (1996) estima el efecto de la recuperación del valor real del salario mínimo en la última década en Argentina, Brasil, Chile y Uruguay sobre la distribución salarial en dichos países. Los resultados sugieren que, con excepción de Chile, una parte significativa de la disminución de la desigualdad es explicada por los incrementos en el salario mínimo.

El presente trabajo aporta evidencia adicional para Argentina, para el período comprendido entre 2003 y 2013, utilizando una metodología diferente a las aplicadas en otros estudios para el país. Específicamente, se utilizará el método propuesto por Lee (1999). El análisis se realizará para el total de asalariados, así como para el conjunto de asalariados registrados y no registrados por separado.

\section{Aspectos institucionales del salario mínimo}

El establecimiento de un salario mínimo orientado a fijar un umbral para las remuneraciones de los asalariados, asegurando así a los trabajadores un ingreso mínimo por sus actividades laborales, es una preocupación tanto de carácter nacional como internacional.

En el ámbito internacional, desde la creación de la Organización Internacional del Trabajo (OIT) en 1919, uno de los objetivos sociales a perseguir por la Organización era la "garantía de un salario vital adecuado". En relación a esto, Bronstein (1993) sostiene que "si bien las normas de la OIT no formulan una definición normativa del salario mínimo [...]; de la lectura de estas normas se pudiera considerar que es aquel nivel de salario por debajo del cual las partes en un contrato de trabajo no pueden pactar una remuneración, salvo autorización legal expresa". El Convenio número 26 y el número 131 de la OIT se refieren específicamente a los salarios mínimos. El artículo 1 del Convenio 26 establece que "todo Miembro de la Organización Internacional del Trabajo que ratifique el presente Convenio se obliga a establecer o mantener métodos que permitan la fijación de tasas mínimas de los salarios de los trabajadores empleados en industrias o partes de industria (especialmente en las industrias a domicilio) en las que no exista un régimen eficaz para la fijación de salarios, por medio de contratos colectivos u otro sistema, y en las que los salarios sean excepcionalmente bajos". Por su parte, el artículo 3 del Convenio 131 establece que "para determinar el nivel de los salarios mínimos deberían incluirse, en la medida en que sea posible y apropiado, de acuerdo con la práctica y las condiciones nacionales: (a) las necesidades de 
los trabajadores y de sus familias habida cuenta del nivel general de salarios en el país, del costo de vida, de las prestaciones de seguridad social y del nivel de vida relativo de otros grupos sociales, y (b) los factores económicos, incluidos los requerimientos del desarrollo económico, los niveles de productividad y la conveniencia de alcanzar y mantener un alto nivel de empleo".

En el mismo sentido, en la Reunión de expertos que el Consejo de Administración de la OIT convocó durante su 168.a reunión en Ginebra, febrero-marzo de 1967, se determinó que el salario mínimo "[...] representa el nivel de remuneración por debajo del cual no se puede descender ni de hecho ni de derecho, cualesquiera que sean la modalidad de remuneración o la calificación del trabajador; [...] es el salario que en cada país tiene fuerza de ley y es aplicable bajo pena de sanciones penales $\mathrm{u}$ otras apropiadas. Los salarios mínimos fijados mediante convenios colectivos declarados obligatorios por la autoridad pública, entran dentro de esta definición" (Informe de la Reunión de expertos de 1967, párr. 100).

En cuanto al ámbito nacional, los antecedentes son varios. En 1964 se sanciono la Ley 16.459 mediante la cual se creó el Consejo Nacional de Salario Vital, Mínimo y Móvil con la función esencial de determinar periódicamente el salario vital mínimo (Art. 5). En 1976 la Ley de Contrato de Trabajo definió al Salario Vital, Mínimo y Móvil (SMVM) como "la mejor remuneración que debe percibir en efectivo el trabajador sin cargas de familia, en su jornada legal de trabajo, de modo que le asegure alimentación adecuada, vivienda digna, educación, vestuario, asistencia sanitaria, transporte y esparcimiento, vacaciones y previsión" (Art. 116), y establece que "todo asalariado mayor de dieciocho años tendrá derecho a percibir una remuneración no inferior al salario mínimo vital que se establezca, conforme a la ley y por los organismos respectivos" (Art. 117)). Asimismo, se estableció que esta institución alcanzara a los asalariados mayores de 18 años de edad, y que aquellos entre 16 y 18 años de edad puedan celebran contratos de trabajo con la autorización de sus padres. Por su parte, la Ley de Empleo de 1991 creó el Consejo Nacional del Empleo, la Productividad, y el Salario Mínimo Vital y Móvil, entre cuyas funciones está la de determinar periódicamente el salario mínimo, vital y móvil. Finalmente, el artículo 14 bis de la Constitución Nacional establece que "El trabajo en sus diversas formas gozará de la protección de las leyes, las que asegurarán al trabajador: condiciones dignas y equitativas de labor; jornada limitada; descanso y vacaciones pagados; retribución justa; salario mínimo vital móvil; igual remuneración por igual tarea [...]".

Contando con los antecedentes antes mencionados, la Resolución del Consejo Nacional del Empleo, la Productividad y el Salario Mínimo, Vital y Móvil № 02, a través de la Resolución 2/1993, determinó un valor del salario mínimo de \$200 por mes para el personal mensualizado que cumpliere la jornada legal de trabajo, valor que se mantuvo constante en término nominales desde agosto de 1993 por un lapso de 10 años. A lo largo de dicho período el salario mínimo fue perdiendo operatividad respecto a su función de servir como umbral a partir del cual se fijan las remuneraciones de los asalariados. Comparar el salario mínimo con los ingresos efectivamente pagados en la economía durante los años ‘90, así como calcular el porcentaje de asalariados que recibían un ingreso en el entorno del salario mínimo son algunas maneras de ver esta falta de operatividad. 
En la tabla A.1 del apéndice se observa que, durante la década de 1990 y los primeros años de 2000, el ingreso promedio de los asalariados era aproximadamente 3 veces el valor nominal del salario mínimo. Es decir, el salario mínimo representaba alrededor de un $30 \%$ de las remuneraciones promedio de los asalariados. La relación salario mínimo-ingreso de los asalariados era aún menor si se considera sólo al conjunto de asalariados registrados, y representaba poco menos del 50\% para el caso de los asalariados informales. Por su parte, en la tabla A.2 del apéndice se observa que, entre 1993 y 2001 sólo el 1\% de los asalariados registrados recibían ingresos menores al salario mínimo, y sólo un $20 \%$ salario inferiores a 2 veces el salario mínimo ${ }^{3}$.

Pasados 10 años desde la última actualización del valor del salario mínimo nominal, y como consecuencia de la pérdida generalizada del poder de compra de los salarios producto de la devaluación del peso, en julio de 2003 el Decreto 388/2003 estableció que "resulta[ba] oportuno actualizar el monto del salario mínimo, vital y móvil, de manera escalonada y progresiva, para adecuarlo a la situación socioeconómica [...]". De esta manera se fijó un salario mínimo de \$250 para julio de 2003, con aumentos sucesivos, alcanzando en diciembre de dicho año un valor de $\$ 300$, siempre para los trabajadores mensualizados que cumplen la jornada legal de trabajo a tiempo completo ${ }^{4}$ comprendidos en el artículo $140^{5}$ de la Ley № 24.013. A partir de dicho momento, distintos decretos y resoluciones fijaron aumentos sucesivos del salario mínimo que hicieron que el mismo aumentase, en términos relativos, de manera sustancial desde el 2003 hasta la fecha.

La tabla 3.1 resume la evolución del salario mínimo nominal para el período 1993-2014. Se observa que desde 2003 a la fecha el salario mínimo se ha modificado en numerosas ocasiones, incrementando sustancialmente el valor nominal del mismo. Sólo a un año desde la primera modificación, el valor nominal del salario mínimo era el doble al que había predominado durante los años '90. Más aún, desde la primera modificación en Julio de 2003, hasta la más reciente en Septiembre de 2014, el valor nominal del salario mínimo se incrementó en más de 16 veces.

Adicionalmente, de la tabla 3.1 se observa que, aún cuando se realizaron actualizaciones sistemáticas del valor nominal, la frecuencia de ajuste es variable en el tiempo. Mientras que a comienzos de 2003 el valor nominal del salario mínimo se ajustaba con frecuencia mensual, en los últimos años los mismos se realizaron más distantes en el tiempo. Este hecho se relaciona con que las actualizaciones no están estipuladas por ley, tal como sucede en otros países de la región, sino más bien responden a decisiones de política.

\footnotetext{
${ }^{3}$ Para un mayor análisis del comportamiento del salario mínimo en los años previos a la crisis de 2001-2002 véase Marinakis y Velasco (2006).

${ }^{4}$ El ministerio de trabajo establece que "la duración del trabajo no podrá exceder de ocho horas diarias o cuarenta y ocho horas semanales, para toda persona ocupada por cuenta ajena en explotaciones públicas o privadas, aunque no persigan fines de lucro. La limitación establecida por la ley es máxima [...]. Existen excepciones por horarios, edades, regiones, industrias, etcétera".

${ }^{5}$ El artículo establece que "todos los trabajadores comprendidos en la Ley de Contrato de Trabajo (t. o. 1976), de la Administración Pública Nacional y de todas las entidades y organismos en que el Estado nacional actúe como empleador, tendrán derecho a percibir una remuneración no inferior al salario mínimo, vital y móvil que se establezca de conformidad a lo preceptuado en esta ley".
} 
Tabla 3.1. Evolución del salario mínimo nominal 1993-2014

\begin{tabular}{|c|c|c|c|}
\hline \multicolumn{2}{|c|}{ Vigencia } & \multirow{2}{*}{$\begin{array}{c}\begin{array}{c}\text { Importe } \\
\text { Mensual } \\
\text { (\$ corrientes) }\end{array} \\
200\end{array}$} & \multirow{2}{*}{$\begin{array}{l}\text { Norma General } \\
\text { Resolución 2/1993 }\end{array}$} \\
\hline 1993 & Agosto & & \\
\hline 2003 & Julio & 250 & Decreto 388/2003 \\
\hline 2003 & Agosto & 260 & Decreto 388/2003 \\
\hline 2003 & Septiembre & 270 & Decreto 388/2003 \\
\hline 2003 & Octubre & 280 & Decreto $388 / 2003$ \\
\hline 2003 & Noviembre & 290 & Decreto 388/2003 \\
\hline 2003 & Diciembre & 300 & Decreto 388/2003 \\
\hline 2004 & Enero & 350 & Decreto $1349 / 2003$ \\
\hline 2004 & Septiembre & 450 & Resolución 2/2004 \\
\hline 2005 & Mayo & 510 & Resolución 2/2005 \\
\hline 2005 & Junio & 570 & Resolución 2/2005 \\
\hline 2005 & Julio & 630 & Resolución 2/2005 \\
\hline 2006 & Agosto & 760 & Resolución 2/2006 \\
\hline 2006 & Septiembre & 780 & Resolución 2/2006 \\
\hline 2006 & Noviembre & 800 & Resolución 2/2006 \\
\hline 2007 & Agosto & 900 & Resolución 2/2007 \\
\hline 2007 & Octubre & 960 & Resolución 2/2007 \\
\hline 2007 & Diciembre & 980 & Resolución 2/2007 \\
\hline 2008 & Agosto & 1200 & Resolución 3/2008 \\
\hline 2008 & Diciembre & 1240 & Resolución 3/2008 \\
\hline 2009 & Agosto & 1400 & Resolución 2/2009 \\
\hline 2009 & Octubre & 1440 & Resolución 2/2009 \\
\hline 2010 & Enero & 1500 & Resolución 2/2009 \\
\hline 2010 & Agosto & 1740 & Resolución 2/2010 \\
\hline 2011 & Enero & 1840 & Resolución 2/2010 \\
\hline 2011 & Agosto & 2300 & Resolución 2/2011 \\
\hline 2012 & Septiembre & 2670 & Resolución 2/2012 \\
\hline 2013 & Febrero & 2875 & Resolución 2/2012 \\
\hline 2013 & Agosto & 3300 & Resolución 4/2013 \\
\hline 2014 & Enero & 3600 & Resolución 4/2013 \\
\hline 2014 & Septiembre & 4400 & Resolución 3/2014 \\
\hline
\end{tabular}

\section{Fuente de datos}

El análisis empírico se realiza en base a microdatos de la Encuesta Permanente de Hogares Continua (EPHC) para el período 2003 a 2013, los cuales son provistos por el Instituto Nacional de Estadística y Censos (INDEC). La EPH es la principal encuesta de hogares que se realiza en Argentina y tiene por objeto relevar las características demográficas y socioeconómicas de la población. En su modalidad original, se ha venido realizando desde 1973 mediante la medición puntual en dos ondas anuales (mayo y octubre). A partir de 2003 la EPH comenzó a tener un relevamiento continuo que produce resultados con frecuencia trimestral. La cobertura es sólo para áreas urbanas. 
El universo de análisis estará compuesto por los trabajadores asalariados a tiempo completo (es decir, aquellos que trabajan habitualmente más de 35 horas semanales ${ }^{6}$ ), con ingresos positivos, de entre 16 y 60 años para las mujeres, y 65 para los hombres ${ }^{7}$, residentes en zonas urbanas. En línea con el alcance de la normativa sobre salario mínimo quedan excluidos el servicio doméstico y los beneficiarios de planes de empleo así como los empleados rurales y los docentes del sector público ${ }^{8}$. A su vez, con el fin de evitar que la evolución de la desigualdad se vea afectada por cambios en la composición de la muestra, el análisis se restringe a los aglomerados que están presentes a lo largo de todo el período bajo estudio.

Por último, y en línea con el método de estimación que se explica más adelante, para cada año considerado se eliminó al conjunto de individuos pertenecientes al uno por ciento de ingresos más bajos y más altos de la distribución.

Un aspecto interesante del salario mínimo se relaciona con el alcance del mismo. Dado que por ley la legislación del salario mínimo es sólo aplicable a los trabajadores formales, parecería natural pensar que sólo las remuneraciones de los trabajadores formales se verían afectados por cambios en el salario mínimo. Sin embargo, distintos trabajos a nivel internacional dan evidencia de la existencia de un efecto faro. Es por ello que en el presente trabajo el universo de análisis queda compuesto tanto por los asalariados formales como por los informales. Para diferenciar entre ambos grupos de asalariados se utiliza la definición legal de formalidad: un trabajador asalariado es formal si su empleador le hace descuentos para realizar las contribuciones a la seguridad social.

Para computar la distribución de los ingresos se utilizó el salario mensual percibido por los trabajadores en su ocupación principal. En cuanto al salario mínimo se consideraron los valores establecidos por los decretos y resoluciones del Consejo Nacional del Empleo, la Productividad y el Salario Mínimo, Vital y Móvil. Al momento de comparar ambos montos de salarios hay que tener en cuenta que los ingresos declarados por los individuos corresponden a valores netos mientras que el valor del salario mínimo se estipula de manera bruta. Consecuentemente, en el presente trabajo, y en la misma línea que Maurizio (2014a), se descontaron los aportes personales al monto legal del salario mínimo, logrando de esa manera comparabilidad entre este último y los ingresos de los individuos.

Adicionalmente, existen ciertas dificultades sobre la delimitación de los ingresos laborales según sean inferiores, superiores, o en el entorno del salario mínimo, relacionadas con errores en la declaración de los ingresos por parte de los individuos. Es por ello que se dividió al grupo de asalariados en tres grupos: i) aquellos con salarios menores al salario mínimo, compuesto por quienes declararon salarios inferiores al $90 \%$ del valor nominal del salario mínimo, ii) aquellos con salarios "en el rango del salario mínimo", si declararon salarios entre el $90 \%$ y $110 \%$ del valor del

\footnotetext{
${ }^{6}$ La elección de este grupo de trabajadores de debe a que el salario mínimo mensual se aplica para los asalariados que cumplen la jornada laboral legal.

${ }^{7}$ Ello permitirá concentrar la atención en la población económicamente activa.

${ }^{8}$ Estos últimos, conjuntamente con el servicio doméstico y los empleados rurales tienen regímenes laborales y salariales propios.
} 
salario mínimo, y iii) aquellos con salarios superiores al salario mínimo, si declararon salarios mayores al $110 \%$ del valor del salario mínimo.

Por último, para deflactar los salarios declarados así como los valores del salario mínimo nominal se utilizará el índice de precios al consumidor 9 provincias (IPC-9 provincias: Chubut (RawsonTrelew), Jujuy, La Pampa (Santa Rosa), Misiones (Posada), Neuquén, Salta, San Luis, Santa Fe y Tierra del Fuego) elaborado por el Centro de Estudios para el Desarrollo Argentino (CENDA), debido a las controversias que ha generado la intervención del INDEC respecto de la estimación del IPC.

\section{Metodología}

Para llevar a cabo la estimación del efecto del salario mínimo sobre la distribución ingreso se utilizará el método propuesto por Lee (1999) y empleado por Autor et al. (2010) para Estados Unidos, y Bosch y Manacorda (2010) para México, concentrándonos en las distribuciones salariales a nivel de aglomerado. El método propuesto por Lee (1999) estima el efecto distributivo del salario mínimo dando cuenta de cuál es el impacto de la brecha entre el salario mínimo y el ingreso de un percentil de referencia sobre la dispersión salarial, medida esta última a través de las brechas sucesivas del salario de cada percentil del ingreso respecto al ingreso del percentil de referencia.

La efectividad del salario mínimo en cuanto a los posibles efectos sobre la reducción de la desigualdad salarial está relacionada con la operatividad del mismo, es decir, cómo es el valor del salario mínimo en relación a los salarios efectivamente pagados en la economía. Sin embargo, dada la imposibilidad de conocer cuál sería la distribución salarial en ausencia del salario mínimo, como proxy de operatividad Lee (1999) modela la relación entre la variabilidad en el salario mínimo operativo y la distribución de los salarios observados, especificando una función para la distribución de salarios que hubiese sido observada en ausencia del salario mínimo y a la que denomina como distribución de salarios latente. A tal fin, propone utilizar un modelo censurado que asume que toda persona con un salario latente por debajo del salario mínimo recibe precisamente el salario mínimo.

En el modelo se define como $w_{a t}^{q}$ al logaritmo del salario del percentil $q$-ésimo de la distribución salarial observada del aglomerado $a$ en el momento $t$, y $w_{a t}^{* q}$ al logaritmo del salario del percentil $q$-ésimo de la distribución salarial latente del aglomerado $a$ en el momento $t$.

Adicionalmente en el modelo se supone que existe un percentil $p$ suficientemente alto tal que los salarios de ese percentil o de percentiles superiores no se ven afectados por el salario mínimo, es decir, $w_{a t}^{s}=w_{a t}^{* s}$ para todo $s \geq p$. Consecuentemente, la brecha del logaritmo del salario entre los percentiles $q$ y $p$ se puede expresar como: 


$$
\begin{gathered}
w_{a t}^{q}-w_{a t}^{p}=w_{a t}^{* q}-w_{a t}^{* p} \quad \text { si } w_{a t}^{* q} \geq S M_{t} \\
w_{a t}^{q}-w_{a t}^{p}=S M_{t}-w_{a t}^{p} \quad \text { si } w_{a t}^{* q}<S M_{t}
\end{gathered}
$$

donde $S M_{t}$ es el logaritmo del salario mínimo en el momento $t$.

De la ecuación anterior se observa que la brecha del logaritmo del salario observado entre los percentiles $q$ y $p$ del aglomerado $a$ en el momento $t$ es igual a la brecha del logaritmo de los salarios latentes si el percentil $q$-ésimo se encuentra por encima del salario mínimo (la distribución de salarios observada es la latente), o de lo contrario, es igual a la diferencia entre el salario mínimo y el $p$-ésimo percentil, si el percentil $q$-ésimo de la distribución latente se encuentra por debajo del salario mínimo (el salario mínimo censura la distribución). El supuesto de que el percentil $p$ o percentiles superiores no se ven afectados por el salario mínimo, es el que permite reemplazar el percentil latente $p$ por el observado en la segunda parte de la ecuación (1).

Lee (1999) llama "salario mínimo efectivo" a la diferencia $S M_{t}-w_{a t}^{p}$ por ser un salario mínimo relativo a un nivel de ingreso que no se ve afectado por cambios en el salario mínimo, y considera al percentil 50 como el percentil $p$ suficientemente alto, en cuyo caso el salario mínimo efectivo es esencialmente una medida del salario mínimo real.

A fin de hacer operativa la ecuación (1) se expresa $w_{a t}^{q}-w_{a t}^{p}$ en función de la brecha de salarios latentes más el efecto del salario mínimo. Adicionalmente, para lograr identificación es necesario imponer cierta parametrización a las diferencias salariales latentes (Bosch y Manacorda, 2010). Lee (1999) parametriza la dispersión salarial latente sólo mediante la inclusión de dummies temporales, de modo que: $w_{a t}^{q}-w_{a t}^{p}=\alpha_{t}^{q}+\beta^{q}\left[S M_{t}-w_{a t}^{p}\right]+\mu_{a q t}, \mathrm{y}$ asume que ante la ausencia del salario mínimo, la distribución salarial latente sería igual, en todos los estados (aglomerados en el presente trabajo), es decir: $w_{j t}^{q *}-w_{j t}^{p *}=w_{k t}^{q *}-w_{k t}^{p *} \forall j, k$ estados.

Sin embargo, si el nivel de salarios promedio de cada estado está sistemáticamente correlacionado con el nivel de desigualdad latente en el mismo, la omisión de efectos fijos a nivel aglomerado en la especificación anterior, podría arrojar estimaciones sesgadas sobre los efectos distributivos del salario mínimo. Al respecto, Bosch y Manacorda (2008) sostienen que "si los [aglomerados] con salarios promedios más altos también presentan mayor desigualdad latente, uno podría encontrar que en esos municipios la operatividad del salario mínimo es menor y la desigualdad más alta, dando lugar a una cierta correlación espúrea negativa entre el salario mínimo efectivo y la desigualdad". Por consiguiente, adhieren al método de Lee (1999), y asumiendo que las diferencias salariales latentes varían al mismo ritmo entre aglomerados, expresan la brecha salarial latente en cada momento del tiempo como $w_{a t}^{* q}-w_{a t}^{* p}=\alpha_{a}^{q}+\alpha_{t}^{q}+X_{a t}^{\prime} \gamma^{q}$, donde $\alpha_{a}^{q}$ y $\alpha_{t}^{q} \mathrm{y}$ son efectos fijos a nivel aglomerado y período, respectivamente, $\mathrm{y} X$ controles a nivel aglomerado que varían por período. 
El modelo de regresión queda expresado como:

$$
w_{a t}^{q}-w_{a t}^{p}=\alpha_{a}^{q}+\alpha_{t}^{q}+\beta^{q}\left[S M_{t}-w_{a t}^{p}\right]+X_{a t}^{\prime} \gamma^{q}+\mu_{a q t}{ }^{9}
$$

donde $\beta^{q}$ captura el efecto del salario mínimo en el percentil $q$.

Un supuesto del modelo es que los salarios de los individuos pertenecientes al percentil $p$ de la distribución, o percentiles superiores no se ven afectados por cambios en el salario mínimo, lo que implica que para dichos percentiles debería observarse $\beta^{q}=0$ para todo $s \geq p^{10}$.

Como fuente de identificación del impacto distributivo del salario mínimo, en el presente trabajo se explota la variación cross-section entre aglomerados de la operatividad del salario mínimo. Esta variabilidad en la operatividad se relaciona con la existencia de un único salario mínimo para todo el país, mientras que los niveles de salarios efectivamente pagados varían entre aglomerados. Por lo tanto, es esperable que el salario mínimo tenga mayor impacto sobre la distribución salarial de los aglomerados con menores niveles de salario. Los aglomerados con niveles de salario más altos, para los cuales el salario mínimo no resulta operativo, y por lo tanto las brechas salariales no varían ante cambios en el valor del salario mínimo son los que permiten identificar la distribución latente.

En el gráfico 5.1 se presenta el grado de operatividad del salario mínimo entre aglomerados para cada año. Específicamente se representa para cada año y cada aglomerado cuál es el percentil del ingreso a partir del cual los asalariados tienen remuneraciones superiores al salario mínimo nominal. En el eje horizontal se representan los años, mientras que el eje vertical refleja los distintos percentiles de salarios. Se observa que existe gran variabilidad respecto a la operatividad del salario mínimo entre los aglomerados para cada año. Por ejemplo, si se considera el año 2004 se observa que en Ushuaia-Río Grande sólo el 3\% de asalariados recibía una remuneración igual o menor al salario mínimo, mientras que dicho porcentaje ascendía al 43\% para Gran Resistencia. Dicha diferencia en los porcentajes confirma la existencia de variabilidad cross-section a nivel aglomerado en la operatividad del salario mínimo. A lo largo de los años esta diferencia se mantiene, siendo siempre Ushuaia-Río Grande el aglomerado para el cual es salario mínimo es menos operativo, al punto que en 2009, 2010, 2012 y 2013 todos los asalariados ganaban más que el salario mínimo, mientras que entre los aglomerados para los cuales el salario mínimo es más operativo se encuentran: Gran Resistencia, Corrientes, Santiago del Estero y Gran Tucumán ${ }^{11}$.

\footnotetext{
${ }^{9}$ Donde $\mu_{\text {aqt }}$ se supone ortogonal a $\left[S M_{t}-w_{a t}^{p}\right]$.

${ }^{10}$ Este es un supuesto testeable. Su rechazo implicaría que el salario mínimo efectivo es endógeno al término de error, afectando por lo tanto la consistencia de las estimaciones (Bosch y Manacorda, 2010).

${ }^{11}$ Si se restringe el análisis sólo a los asalariados formales, la variación cross-section de operatividad del salario mínimo es menor, aunque sigue siendo de importante magnitud. Gráfico A.1 del apéndice.
} 
Gráfico 5.1. Operatividad del salario mínimo por año y aglomerado

Total asalariados

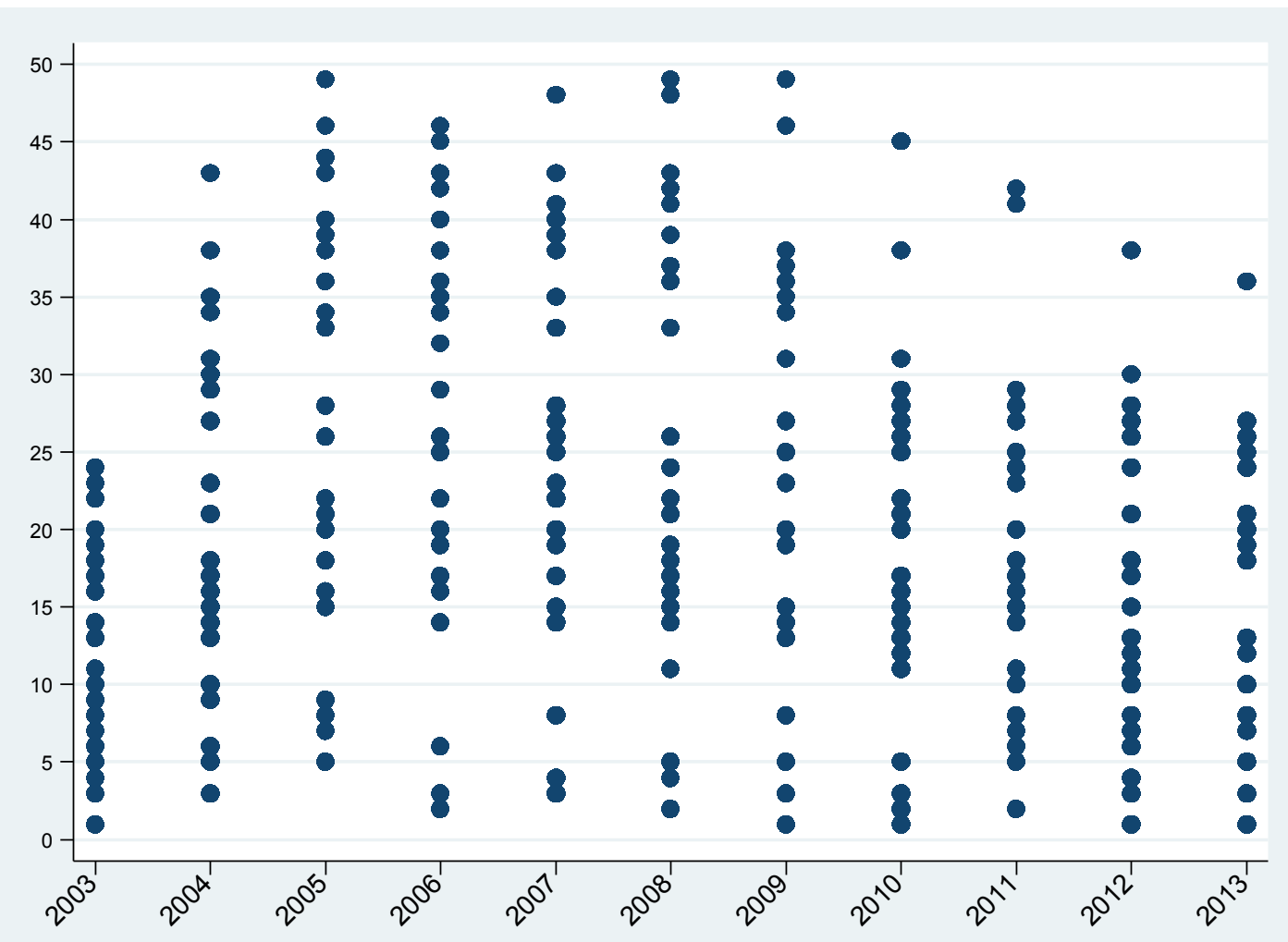

Fuente: Consejo Nacional de Empleo, la Productividad, y el Salario Mínimo, Vital y Móvil e INDEC.

Nota: Cada observación corresponde a un aglomerado y representa la operatividad del salario mínimo entendida como el percentil del ingreso a partir del cual los asalariados obtienen remuneraciones superiores al salario mínimo nominal, utilizando información del 4to trimestre de la EPHC.

Un problema del método de estimación presentado anteriormente es que adolece del problema de "Division bias" (Borjas, 1980) debido a la inclusión del nivel de salario del percentil de referencia, $w_{a t}^{p}$, tanto en las medidas de dispersión de ingresos, esto es, la variables dependiente $\left[w_{a t}^{q}-w_{a t}^{p}\right]$, como en la construcción del salario mínimo efectivo, la variables independiente $\left[S M_{t}-w_{a t}^{p}\right]$. Cualquier error de medición en los salarios del percentil de referencia conducirá a una correlación espúrea positiva entre las medidas de desigualdad y la medida de salario mínimo efectivo y por lo tanto a una estimación sesgada al alza del efecto del salario mínimo (Bosch y Manacorda, 2008; Autor et al., 2010).

Lee (1999) reconoce este problema por lo que utiliza dos medidas diferentes: el salario mediano para la construcción de la variable dependiente, y una medida de centralidad alternativa, la media truncada del salario, calculada luego de eliminar a los 30 percentiles más bajos y más altos de la distribución para cada aglomerado y año, para la variable independiente. 
Bosch y Manacorda (2008) proponen un forma alternativa de hacer frente al problema de "Division bias", y es el que se utilizará en el presente trabajo. Los autores instrumentan el salario mínimo efectivo $\left[S M_{t}-w_{a t}^{p}\right]$ con el salario mínimo efectivo calculado a partir de salarios rezagados $\left[S M_{t}-w_{a t-1}^{p}\right]$, esto es, el logaritmo del salario mínimo actual menos el logaritmo del salario del percentil de referencia rezagado un año, para el mismo aglomerado. Esta estrategia estará libre del problema de "Division bias" siempre que el error de medición no esté correlacionado a través del tiempo dentro de cada aglomerado, condicional en dummies temporales y efectos fijos a nivel aglomerado.

Un último aspecto a determinar relacionado con el modelo es definir cuál es el percentil $p$ suficientemente alto tal que los salarios de ese percentil y de los percentiles superiores no se ven afectados por cambios en el salario mínimo. Bosch y Manacorda (2010) sostienen que para México, a diferencia de Estados Unidos donde Lee (1999) utiliza $p=50$, el salario mínimo tiene más allá de la mediana, utilizando para sus estimaciones el salario del percentil $70(p=70)$ como percentil de referencia. Específicamente los autores sostienen que "la razón para utilizar el séptimo decil en comparación con la mediana, es que, en al menos algunas especificaciones, encontramos evidencia de ganancias significativas hasta el sexto decil producto del salario mínimo".

En el presente trabajo se utiliza al percentil 80 como el percentil de referencia. Cabe la pena mencionar que, aún cuando el mismo puede resultar demasiado alto, a lo largo del período el salario mínimo representaba alrededor del $40 \%$ del ingreso de dicho percentil para el total de asalariados, es decir, el ingreso del percentil 80 fue poco más de 2 veces el salario mínimo. Si se considera sólo las remuneraciones de los asalariados formales el salario mínimo representa menos en relación al ingreso del percentil 80 pero sigue siendo de alrededor del 35\%. La relación asciende a aproximadamente el $60 \%$ para los asalariados informales ${ }^{12}$.

\section{Salario mínimo y desigualdad salarial: algunas estadísticas descriptivas}

Como se menciono anteriormente, el establecimiento de un mínimo salarial tiene por objetivo fijar un umbral a los ingresos de los trabajadores más vulnerables. Adicionalmente, el salario mínimo puede ser usado para lograr una mejora distributiva siempre que mediante su establecimiento se genere una compresión en la distribución salarial. La efectividad del salario mínimo en cuanto a cumplir estos objetivo está estrechamente relacionada con la estructura de salarios de la economía. En este sentido, es relevante determinar cuál es la población afectada por el salario mínimo, es decir, aquella que recibe remuneraciones en el entorno del salario mínimo, así como comparar el valor de la institución del salario mínimo con la estructura de remuneraciones vigente en la economía.

\footnotetext{
12 La tabla A.3 del apéndice resume la relación entre el salario mínimo y el ingreso del percentil 80 para el período 20032013, para el total de asalariados, para los asalariados formales y para los asalariados informales.
} 


\subsection{Salario mínimo, índice de precios y estructura de las remuneraciones}

Los aumentos del salario mínimo nominal experimentados a partir de 2003 dieron lugar a una marcada actualización del salario mínimo real. El gráfico 6.1 presenta la evolución del mismo para el período bajo estudio, conjuntamente con la línea de tendencia del valor real.

Gráfico 6.1. Evolución del salario mínimo real 2003-2013

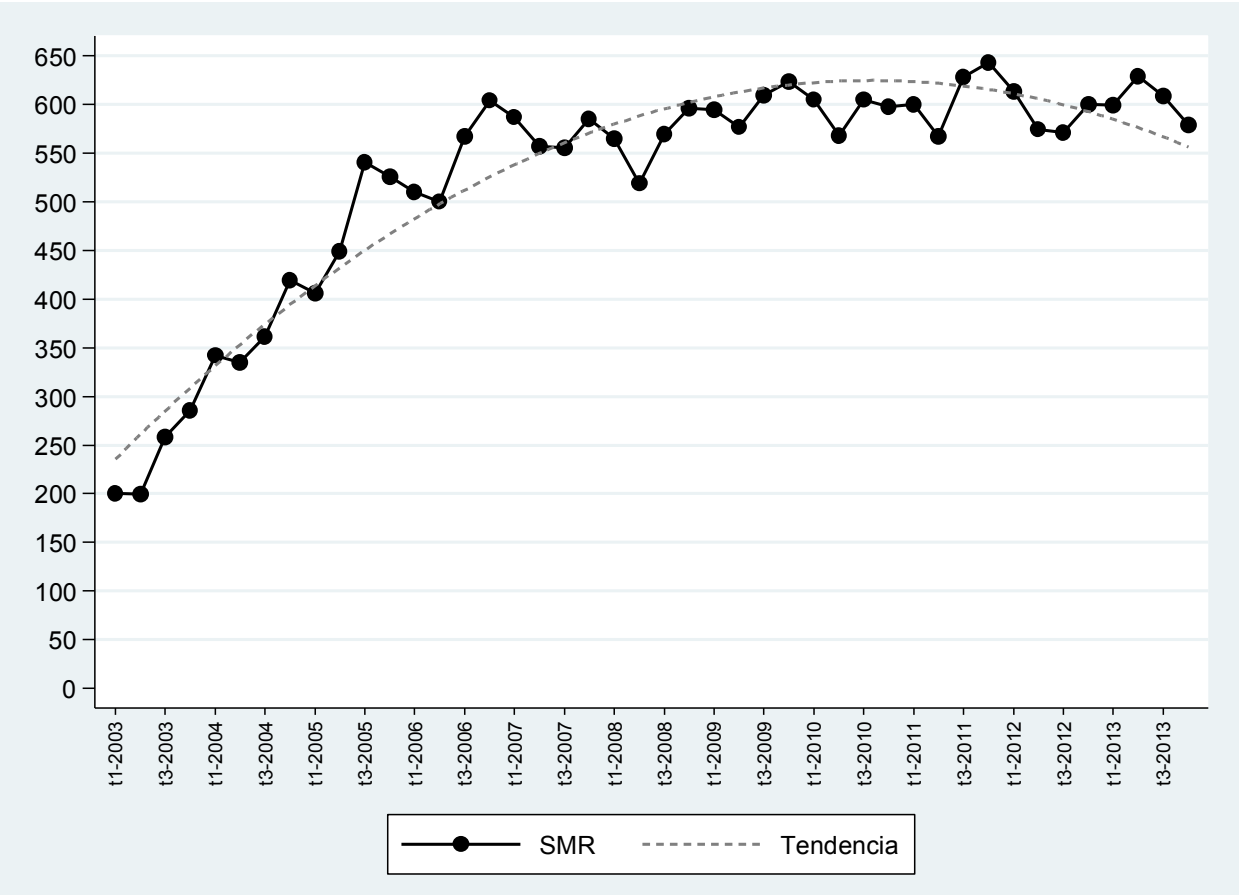

Fuente: Consejo Nacional de Empleo, la Productividad, y el Salario Mínimo, Vital y Móvil, y CENDA.

Del gráfico anterior se observa un fuerte incremento del salario mínimo real a lo largo de la primera década del 2000, triplicando al final del período analizado el valor real observado a comienzos de 2003. Sin embargo dicho aumento se debe principalmente a la trayectoria creciente que el salario mínimo tuvo durante los primeros años, de 2003 a 2007. A partir de 2008, y hasta comienzos de 2012 (a partir de ese año comienza a observarse una tendencia decreciente en el valor del salario mínimo real), la recuperación del poder adquisitivo de los ingresos comenzó un período de relativo estancamiento producto de la aceleración de la inflación (Beccaria Y Maurizio, 2012), con períodos de aumentos y otros de descensos del valor real del salario mínimo, aún cuando el valor nominal del mismo aumentó de manera sostenida durante todo el período. Este relativo estancamiento del salario mínimo real a partir de 2008 se relaciona con 2 hechos: trimestres para los cuales el salario mínimo nominal se mantuvo constante mientras que los precios aumentaron, o bien, trimestres para los cuales el aumento del salario mínimo nominal fue menor al aumento de los precios. 
El comportamiento antes mencionado está relacionado con la frecuencia de ajuste del valor del salario mínimo nominal. Tal como se mencionó anteriormente, si bien el salario mínimo nominal aumentó de manera sostenida a lo largo de todo el período, lo hizo con frecuencia variable en el tiempo producto de las actualizaciones no se realizaron siguiendo alguna ley o criterio, sino más bien de manera discrecional por parte del gobierno. Más aún, los ajustes del valor nominal en los últimos años han sido más espaciados en el tiempo.

Tan interesante como estudiar la evolución del salario mínimo real resulta analizar el valor del salario mínimo en relación a la estructura de remuneraciones vigente en la economía a fin de evaluar si el valor del salario mínimo resulta consistente con la misma, así como para comparar la evolución del salario mínimo respecto a la evolución de las remuneraciones. Un salario mínimo cuyo valor nominal resulte demasiado bajo respecto a las remuneraciones efectivamente pagadas no cumplirá con su función de umbral para los ingresos de los individuos, tal como sucedió en la década del '90, mientras que el establecimiento de un salario mínimo muy elevado puede aumentar el no cumplimiento del mismo.

A fin de evaluar esta cuestión, se comparó el valor del salario mínimo con distintos puntos de la distribución de los salarios: el percentil 10, el percentil 20, el salario mediano de la economía y el salario promedio, para el total de asalariados, para los asalariados formales, y para los informales. Las tablas 6.1, 6.2 y 6.3 resumen dicha información.

Tabla 6.1. Salario mínimo y estructura de remuneraciones Total de asalariados (en porcentajes)

\begin{tabular}{ccccc}
\hline & $\begin{array}{c}\text { SM/Salario } \\
\text { promedio }\end{array}$ & $\begin{array}{c}\text { SM/Salario } \\
\text { mediano }\end{array}$ & $\begin{array}{c}\text { SM/Salario } \\
\text { p10 }\end{array}$ & $\begin{array}{c}\text { SM/Salario } \\
\text { p20 }\end{array}$ \\
\hline 2003 & 18.0 & 38.6 & 83.2 & 63.2 \\
2004 & 25.9 & 55.6 & 118.7 & 88.8 \\
2005 & 31.0 & 64.1 & 127.9 & 102.4 \\
2006 & 31.4 & 65.7 & 130.2 & 97.6 \\
2007 & 31.2 & 64.9 & 128.1 & 98.4 \\
2008 & 32.5 & 63.4 & 124.9 & 94.0 \\
2009 & 32.4 & 60.5 & 114.5 & 90.4 \\
2010 & 29.7 & 58.6 & 114.9 & 89.0 \\
2011 & 30.6 & 59.3 & 112.8 & 89.5 \\
2012 & 30.4 & 55.3 & 104.9 & 78.8 \\
2013 & 28.3 & 52.9 & 96.6 & 77.4 \\
\hline
\end{tabular}

Fuente: Consejo Nacional de Empleo, la Productividad, y el Salario Mínimo, Vital y Móvil e INDEC.

Nota: En la tabla se presenta la relación (en \%) del salario mínimo con distintos puntos de la distribución salarial, utilizando información del 4to trimestre de la EPHC.

De la tabla 6.1 se observa que durante el período estudiado se produjo un aumento del valor del salario mínimo respecto al ingreso promedio del total de asalariados de poco más de 14 puntos porcentuales (p.p.), de $18 \%$ a $28.3 \%$. Sin embargo, dicha relación no presenta una trayectoria 
constante a lo largo del tiempo. Por el contrario, el incremento observado se debe principalmente al aumento de la relación salario mínimo - ingreso promedio experimentado entre los años 2003 y 2004, de 8 p.p., y entre 2004 y 2005, donde la relación ascendió al 31\%. En los años posteriores, y hasta 2010 cuando la relación comenzó una tendencia decreciente, se observa un relativo estancamiento. Al respecto, Maurizio (2014a) sostiene que "en la medida en que la aceleración de la inflación fue debilitando los aumentos reales que esta institución había registrado hasta ese momento, ello también se tradujo en cierta pérdida de operatividad en relación a la distribución salarial".

Un panorama similar se observa cuando se mide el salario mínimo en relación al salario mediano de la economía, así como en relación al salario de los primeros deciles de la distribución. En todos los casos se produjo un fuerte crecimiento, explicado por lo acontecido entre 2003 y 2005 . Se observa que para el 2012 y 2013, el salario mínimo representaba aproximadamente la mitad del ingreso mediano, el $75 \%$ del ingreso del percentil 20 , y se ubicaba en el entorno del décimo percentil.

Al comparar el salario mínimo con la estructura de remuneraciones de los asalariados formales, tabla 6.2, se observa una menor importancia relativa del primero en relación con lo reportado para el total de asalariados, aunque con trayectorias similares a lo largo del tiempo. Para el caso de los asalariados registrados, la participación relativa del salario mínimo aumentó poco más de 11 p.p. respecto al salario promedio, 13 p.p. en relación al salario mediano, y 16 p.p. respecto al ingreso de los percentiles 10 y 20.

Tabla 6.2. Salario mínimo y estructura de remuneraciones Asalariados formales (en porcentajes)

\begin{tabular}{lcccc}
\hline & $\begin{array}{c}\text { SM/Salario } \\
\text { promedio }\end{array}$ & $\begin{array}{c}\text { SM/Salario } \\
\text { mediano }\end{array}$ & $\begin{array}{c}\text { SM/Salario } \\
\text { p10 }\end{array}$ & $\begin{array}{c}\text { SM/Salario } \\
\text { p20 }\end{array}$ \\
\hline 2003 & 15.8 & 33.7 & 61.7 & 50.4 \\
2004 & 23.4 & 47.6 & 85.4 & 72.3 \\
2005 & 27.8 & 55.6 & 92.9 & 79.1 \\
2006 & 29.1 & 57.1 & 94.6 & 80.2 \\
2007 & 28.4 & 55.8 & 96.2 & 79.6 \\
2008 & 28.5 & 56.2 & 93.8 & 78.5 \\
2009 & 29.4 & 55.3 & 88.6 & 75.7 \\
2010 & 28.1 & 51.3 & 89.9 & 73.1 \\
2011 & 27.6 & 53.1 & 91.9 & 75.2 \\
2012 & 28.6 & 49.2 & 80.7 & 69.6 \\
2013 & 27.3 & 46.2 & 77.1 & 66.7 \\
\hline
\end{tabular}

Fuente: Consejo Nacional de Empleo, la Productividad, y el Salario Mínimo, Vital y Móvil e INDEC.

Nota: En la tabla se presenta la relación (en \%) del salario mínimo con distintos puntos de la distribución salarial, utilizando información del 4to trimestre de la EPHC. 
Una participación relativa mucho mayor del salario mínimo se observa cuando se lo compara con la estructura de ingresos de los asalariados informales (tabla 6.3). De las tablas 6.2 y 6.3 se observa que mientras que el salario mínimo representó a lo largo del período de estudio poco más del 50\% del salario mediano de los asalariados formales, prácticamente equiparó las remuneraciones medianas de los asalariados informales.

Adicionalmente, al comparar el salario mínimo con los percentiles más bajos de la distribución de ingresos de los asalariados informales se observa que la relación respecto al percentil 10 es de aproximadamente el $200 \%$ para todo el período, reflejando la gran brecha salarial entre trabajadores formales e informales, especialmente en la parte inferior de la distribución.

Tabla 6.3. Salario mínimo y estructura de remuneraciones Asalariados informales (en porcentajes)

\begin{tabular}{ccccc}
\hline & $\begin{array}{c}\text { SM/Salario } \\
\text { promedio }\end{array}$ & $\begin{array}{c}\text { SM/Salario } \\
\text { mediano }\end{array}$ & $\begin{array}{c}\text { SM/Salario } \\
\text { p10 }\end{array}$ & $\begin{array}{c}\text { SM/Salario } \\
\text { p20 }\end{array}$ \\
\hline 2003 & 46.8 & 55.7 & 121.7 & 88.2 \\
2004 & 65.8 & 83.4 & 180.1 & 128.8 \\
2005 & 82.6 & 95.2 & 193.9 & 144.6 \\
2006 & 84.4 & 98.4 & 200.0 & 152.4 \\
2007 & 83.5 & 99.3 & 211.4 & 158.6 \\
2008 & 84.0 & 93.1 & 200.5 & 151.7 \\
2009 & 85.4 & 92.1 & 219.5 & 152.0 \\
2010 & 78.2 & 89.3 & 162.8 & 131.6 \\
2011 & 79.5 & 94.3 & 183.0 & 132.0 \\
2012 & 73.3 & 78.6 & 154.0 & 116.4 \\
2013 & 70.1 & 74.1 & 157.4 & 115.9 \\
\hline
\end{tabular}

Fuente: Consejo Nacional de Empleo, la Productividad, y el Salario Mínimo, Vital y Móvil e INDEC.

Nota: En la tabla se presenta la relación (en \%) del salario mínimo con distintos puntos de la distribución salarial, utilizando información del 4to trimestre de la EPHC.

\subsection{Alcance del salario mínimo}

Otro aspecto relevante a la hora de estudiar los posibles efectos del salario mínimo sobre la distribución salarial es identificar cuál es la población potencialmente afectada por los cambios en el mismo, es decir, determinar cuál es la población que recibe salarios en el entorno del salario mínimo.

Una forma gráfica de visualizar el alcance del salario mínimo es mediante los gráficos de función de densidad de Kernel. El gráfico 6.2 reporta las funciones de densidad del logaritmo de los salarios mensuales de los asalariados a tiempo completo, para el período 2003-2013 utilizando un Kernel epanechnikov con ancho de banda óptimo. Las líneas verticales representa el valor del salario mínimo nominal de cada año. 
Del gráfico se observa como el salario mínimo fue ganando operatividad a lo largo del período, creando un soporte para la distribución salarial, particularmente hasta el año 2007. Para ese año una gran parte de la distribución salarial se concentraba alrededor del salario mínimo. Para los años posteriores, donde el aumento del valor real del salario mínimo comenzó a verse interrumpido por el aumento sostenido de la inflación, se observa cómo el salario mínimo va perdiendo operatividad.

Gráfico 6.2. Distribución salarial y salario mínimo $2003-2013$ - Total asalariados
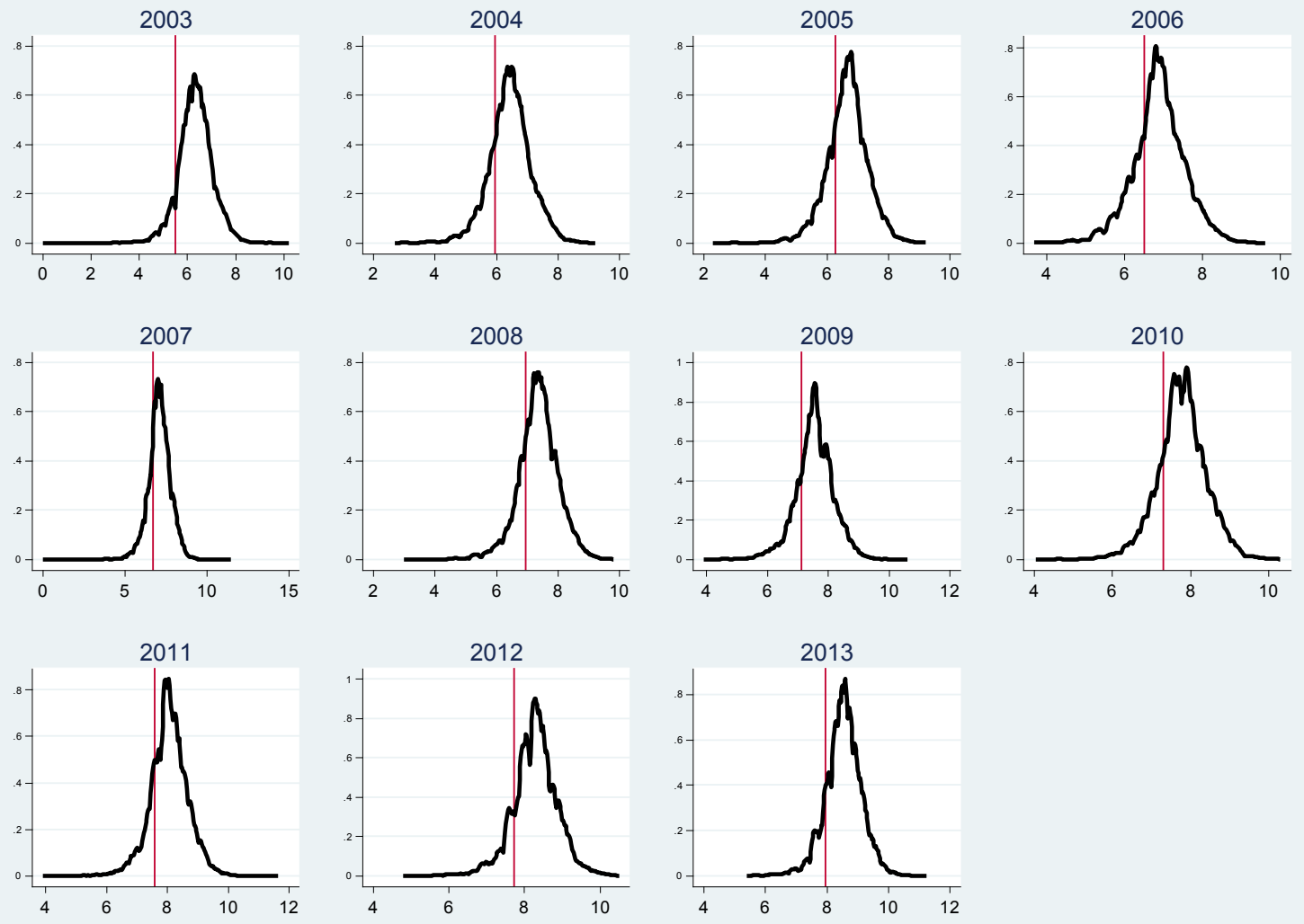

Fuente: Consejo Nacional de Empleo, la Productividad, y el Salario Mínimo, Vital y Móvil e INDEC.

Nota: La figura representa la distribución de salarios del total de asalariados a tiempo completo, para el 4to trimestre de cada año. Las líneas verticales se refieren al nivel de los salarios mínimos, también para el 4to trimestre.

Al dividir el análisis entre asalariados registrados y no registrados, gráfico 6.3, el comportamiento del salario mínimo y las distribuciones salariales de los asalariados registrados resulta similar al evidenciado para el total de asalariados. Del gráfico 6.3 se observa que desde 2003 hasta 2007 el salario mínimo gana operatividad en relación a la distribución de ingresos de los asalariados formales, quedando sólo una pequeña proporción de la distribución por debajo del valor del 
salario mínimo ${ }^{13}$. A partir de 2007 el salario mínimo queda un poco rezagado, tal como se mencionó previamente en el trabajo. De las funciones de densidad de los asalariados no registrados se observa que sólo para el año 2003 parecería existir cierta operatividad del salario mínimo. A partir de 2004 alrededor de la mitad de la distribución queda por debajo del valor nominal del salario mínimo.

Gráfico 6.3. Distribución salarial y salario mínimo

2003 - 2013 - Asalariados formales e informales
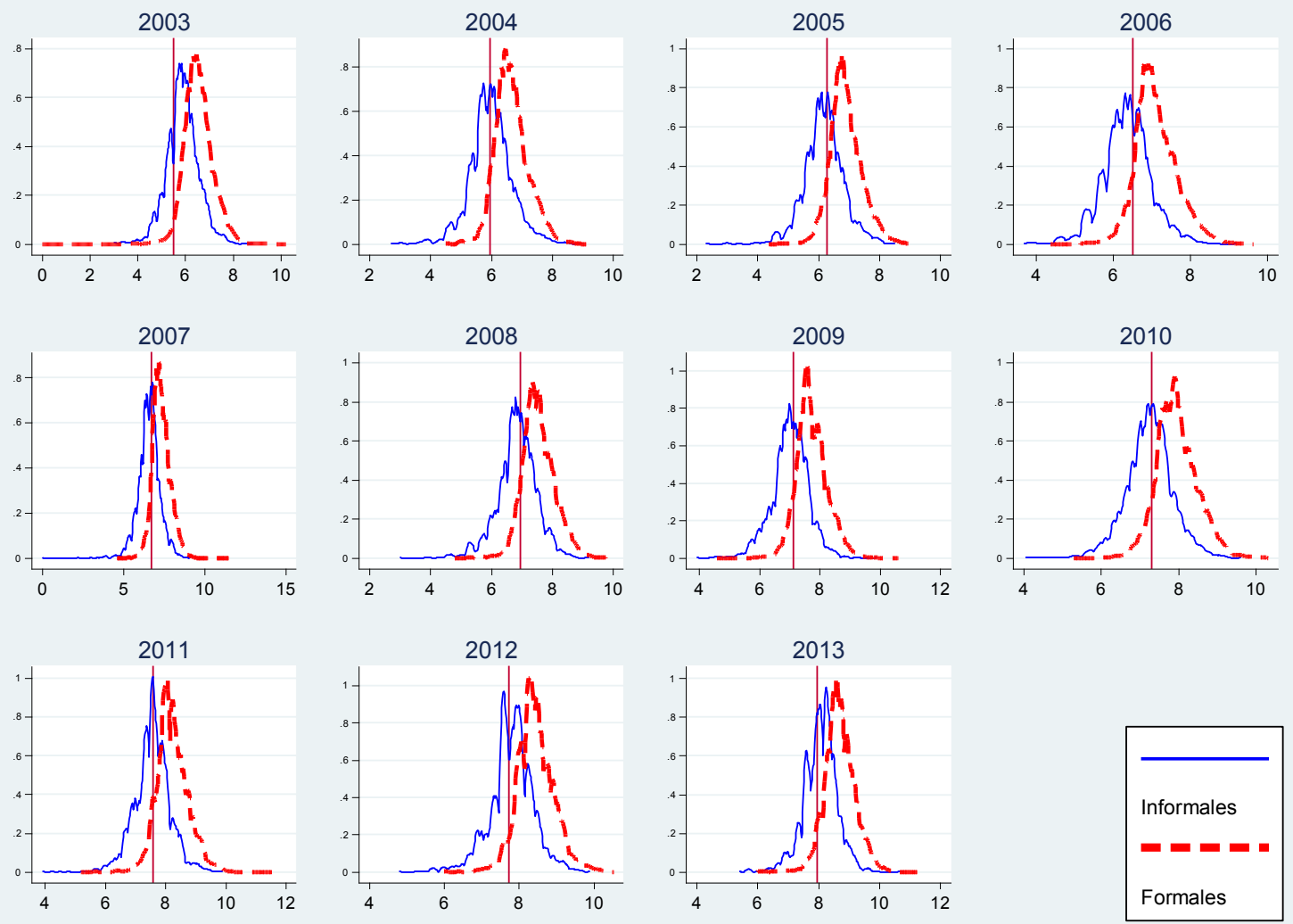

Fuente: Consejo Nacional de Empleo, la Productividad, y el Salario Mínimo, Vital y Móvil e INDEC.

Nota: La figura representa la distribución de salarios de los asalariados a tiempo completo según su condición de formalidad, para el 4to trimestre de cada año. Las líneas verticales se refieren al nivel de los salarios mínimos, también para el 4to trimestre.

Conjuntamente con el análisis gráfico, y a los efectos de identificar a la población posiblemente afectada por los cambios en el salario mínimo se dividió al grupo de los asalariados en 3 grupos: el grupo de asalariados con ingresos inferiores al salario mínimo, aquellos con salarios en el entorno

\footnotetext{
${ }^{13}$ A priori y bajo el cumplimiento de la ley, ningún asalariado registrado que cumpla jornada laboral completa tendría que recibir un ingreso inferior al salario mínimo. Por lo tanto, la parte de la distribución salarial que queda por debajo del salario mínimo puede reflejar errores de declaración de los ingresos por parte de los individuos. Adicionalmente, Groisman (2012) sostiene que este hecho "puede resultar del retraso o incumplimiento en la aplicación efectiva del salario mínimo".
} 
del salario mínimo, y los asalariados con remuneraciones superiores. Una vez más, el análisis se realiza para el total de los asalariados, así como para los asalariados formales y asalariados informales, por separado.

La tabla 6.4 resume la información para el total de asalariados así como para los asalariados formales e informales por separado, para cada uno de los años considerados. Se observa que, sin considerar el año 2003, menos de un cuarto del total de asalariados reciben remuneraciones inferiores o iguales al salario mínimo. Si bien la población potencialmente afectada a cambios es el salario mínimo es aquella que recibe ingresos en el rango del mismo, puede considerarse dentro de este grupo a la población con remuneraciones menores al salario mínimo, bajo la hipótesis de que están en dicha situación por un retraso en el cumplimiento de la institución del salario mínimo. Bajo este supuesto, de la evolución de la población posiblemente afectada (es decir, aquellos con ingresos inferiores y en el rango del salario mínimo) se observa que la misma aumentó entre 2003 y 2007, cuando llegó a representar aproximadamente el 30\% de los asalariados. Groisman (2012) sostiene que este comportamiento guarda relación con la notoria actualización del valor nominal del salario mínimo durante dicho período. A partir de 2007 cada vez fue mayor el porcentaje de asalariados con remuneraciones superiores al salario mínimo lo cual se corresponde con el período de relativo estancamiento del valor real del mismo.

Tabla 6.4. Alcance del salario mínimo por tramos de ingresos (en porcentaje) $2003-2013$

\begin{tabular}{|c|c|c|c|c|c|c|c|c|c|}
\hline \multirow[b]{2}{*}{ Año } & \multicolumn{3}{|c|}{ Total Asalariados } & \multicolumn{3}{|c|}{ Asalariados Formales } & \multicolumn{3}{|c|}{ Asalariados Informales } \\
\hline & $\begin{array}{c}\text { Inferior al } \\
\text { SM }\end{array}$ & $\begin{array}{c}\text { En el entorno } \\
\text { del SM }\end{array}$ & $\begin{array}{c}\text { Superior al } \\
\text { SM }\end{array}$ & $\begin{array}{l}\text { Inferior al } \\
\text { SM }\end{array}$ & $\begin{array}{c}\text { En el entorno } \\
\text { del SM }\end{array}$ & $\begin{array}{c}\text { Superior al } \\
\text { SM }\end{array}$ & $\begin{array}{c}\text { Inferior al } \\
\text { SM }\end{array}$ & $\begin{array}{c}\text { En el entorno } \\
\text { del SM }\end{array}$ & $\begin{array}{c}\text { Superior al } \\
\text { SM }\end{array}$ \\
\hline 2003 & 6.0 & 2.4 & 91.6 & 1.5 & 0.9 & 97.6 & 15.7 & 5.6 & 78.8 \\
\hline 2004 & 12.2 & 9.6 & 78.2 & 2.8 & 6.2 & 91.0 & 32.1 & 16.7 & 51.2 \\
\hline 2005 & 15.8 & 7.1 & 77.0 & 5.0 & 4.9 & 90.2 & 39.5 & 12.1 & 48.4 \\
\hline 2006 & 19.0 & 6.1 & 75.0 & 6.5 & 5.2 & 88.3 & 47.4 & 8.0 & 44.6 \\
\hline 2007 & 15.6 & 11.3 & 73.1 & 5.6 & 8.7 & 85.7 & 40.6 & 17.8 & 41.6 \\
\hline 2008 & 14.2 & 7.8 & 77.9 & 5.5 & 6.0 & 88.5 & 38.5 & 12.9 & 48.6 \\
\hline 2009 & 13.9 & 7.3 & 78.9 & 5.0 & 5.1 & 90.0 & 39.5 & 13.6 & 46.8 \\
\hline 2010 & 12.6 & 8.9 & 78.5 & 5.0 & 6.0 & 89.0 & 35.2 & 17.7 & 47.1 \\
\hline 2011 & 11.7 & 10.4 & 77.9 & 4.1 & 6.9 & 89.0 & 35.0 & 20.9 & 44.1 \\
\hline 2012 & 11.3 & 5.8 & 82.9 & 4.3 & 3.7 & 92.0 & 31.6 & 12.1 & 56.3 \\
\hline 2013 & 9.4 & 6.5 & 84.1 & 3.4 & 4.3 & 92.2 & 27.1 & 12.9 & 60.0 \\
\hline
\end{tabular}

Fuente: Consejo Nacional de Empleo, la Productividad, y el Salario Mínimo, Vital y Móvil e INDEC. Nota: En la tabla se presenta el porcentaje de asalariados por rango de ingresos utilizando información del 4to trimestre de la EPHC.

Al dividir el análisis entre asalariados registrados y no registrados el panorama se modifica significativamente. De hecho, mientras que, a lo largo de todo período, más del $85 \%$ de los asalariados formales recibían salarios superiores al mínimo, dicha proporción se reduce al $40 \%$ $50 \%$ al considerar a los asalariados informales, con excepción del años 2013 que ascendió al $60 \%$ y del año 2003 que alcanzó el casi el 79\%. Otra diferencia notable entre ambos grupos es la proporción de cada grupo de asalariados recibiendo ingresos inferiores al salario mínimo. Mientras 
que para el caso de los asalariados registrados esta proporción es de aproximadamente el $5 \%{ }^{14}$ a lo largo del período, asciende a $40 \%$ para los asalariados no registrados.

En relación a los asalariados no registrados, el gran porcentaje de individuos recibiendo remuneraciones menores o iguales al salario mínimo podría estar indicando a priori una ausencia del efecto faro.

En resumen, los gráficos 6.1 y 6.2 así como la tabla 6.4, parecerían indicar cierta relación entre el salario mínimo y la distribución salarial, al menos para el caso del total de asalariados y para los asalariados formales, con efecto sobre la cola inferior de la distribución. De todos modos, si bien la utilización de gráficos de Kernel y la estimación del porcentaje de trabajadores por rangos de ingresos es una manera sencilla de ver cambios en la distribución de ingresos y operatividad del salario mínimo, sólo refleja correlaciones que distan de ser una prueba del efecto causal del salario mínimo sobre la mejora distributiva. Para analizar el efecto se utilizará el método antes presentado. En la sección 7 se presentan los resultados.

\subsection{Evolución de la desigualdad}

Desde comienzos de los años 2000 la Argentina ha experimentado una disminución de la desigualdad de ingresos, principalmente producto de una mejora distributiva en los ingresos laborales (Bertranou y Maurizio, 2011; Trujillo y Villafañe, 2011; Keifman y Maurizio, 2012; Alejo et al. 2013; Azevedo, Inchauste y Sanfelice, 2013).

En esta subsección nos centraremos en estudiar la evolución de la desigualdad salarial, tanto para el total de asalariados como para cada tipo de asalariado dependiendo de su condición de formalidad. La misma se analizará mediante la evolución del índice de Gini. Adicionalmente, y con el fin de evaluar si los cambios en la desigualdad salarial se deben en mayor medida a compresiones en la cola inferior o superior de la distribución, se presentan las tendencias de las brechas entre los ingresos de los percentiles extremos de la distribución, p10 y p90, respecto a la mediana (p50).

El gráfico 6.4 representa la evolución del coeficiente de Gini de los salarios para los distintos grupos de asalariados. Se observa que la desigualdad del total de asalariados, así como de cada uno de los mismos de acuerdo a su condición de formalidad ha disminuido significativamente entre 2003 y 2013.

Al considerar al conjunto de asalariados se verifica una caída del coeficiente de Gini de 8 p.p. a lo largo de todo período analizado, aunque con trayectoria variante en el tiempo, con períodos de mejoras distributivas (2003 a 2006, 2007 a 2009 y 2011 a 2012), otros de estancamiento (2012 a 2013), así como de empeoramiento en la distribución salarial (2006 a 2007 y 2009 a 2011).

\footnotetext{
${ }^{14}$ Tal como se mencionó anteriormente el porcentaje de asalariados registrados recibiendo ingresos menores al salario mínimo puede reflejar errores de declaración de los ingresos por parte de los individuos.
} 
La evolución del coeficiente de Gini de los asalariados es similar, en términos cualitativos a la observada para el total de asalariados, y poco mayor en términos cuantitativos. El coeficiente de Gini para los asalariados formales disminuyó 9 p.p. a lo largo de la década analizada. Para el caso de los asalariados informales la mejora distributiva arrojó una caída de 6 p.p. desde 2003 a 2013, y presentó también una evolución variante a lo largo de los años. Los resultados hallados son consistentes con los encontrados por Azevedo et al. (2013b) quien sostiene que aún cuando en América Latina la desigualdad cayó más dentro del grupo de los informales, en Argentina fueron los asalariados registrados los que experimentaron mayores mejoras.

Gráfico 6.4. Evolución del coeficiente de Gini $2003-2013$

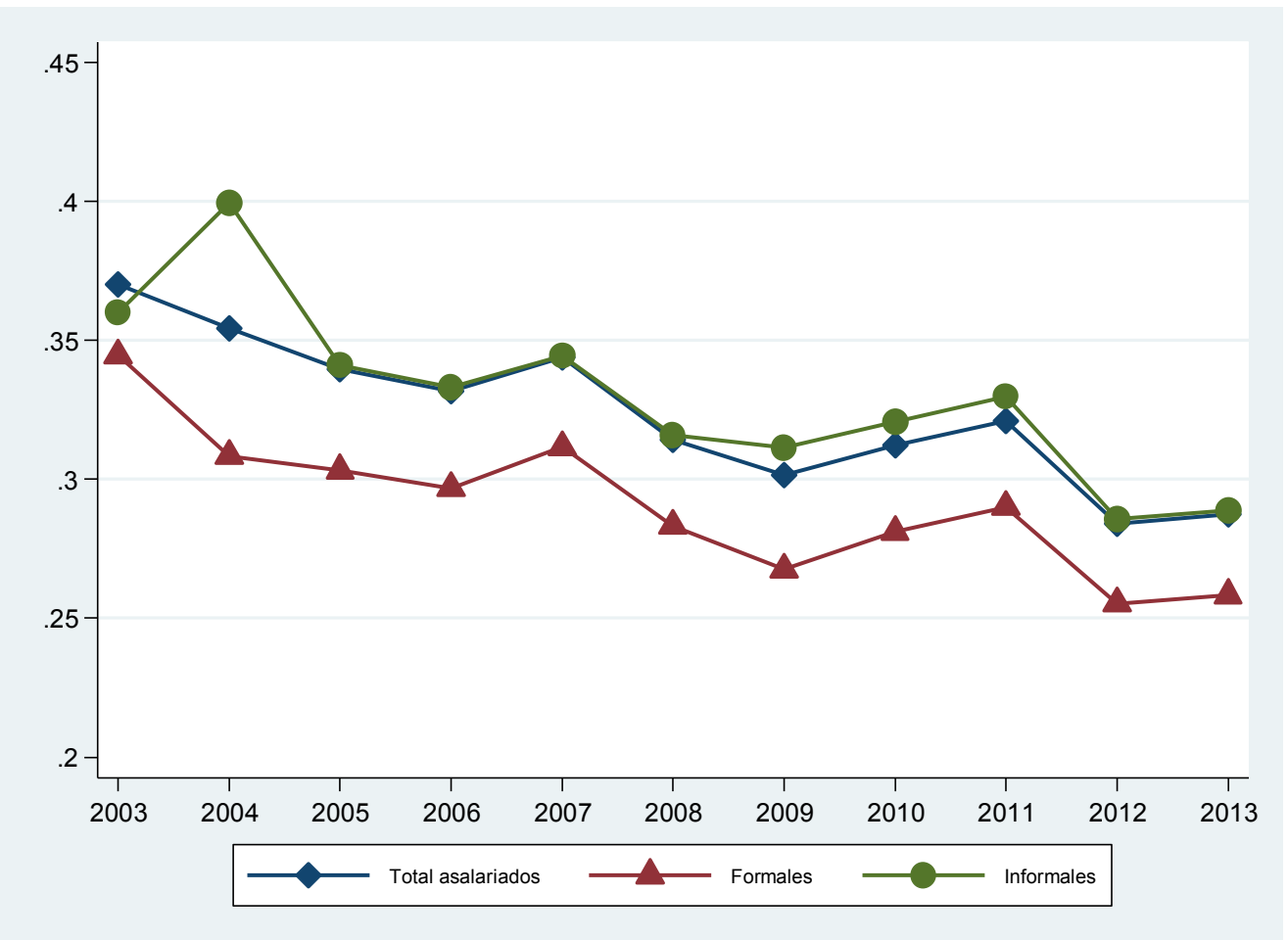

Fuente: INDEC. 4to trimestre de la EPHC.

Del gráfico 6.4 se observa una fuerte caída de la desigualdad salarial en el período considerado. Para conocer si la misma se debe a una mejora distributiva en la parte baja de la distribución o a una compresión salarial en la parte alta, los gráficos $6.5,6.6$ y 6.7 representan las tendencias de las brechas entre el logaritmo del ingreso de los percentiles 10 y 90 respecto al logaritmo del ingreso mediano, para el total de asalariados, para los asalariados formales y los informales, respectivamente. Los valores de las brechas están estandarizados a uno al año 2003. 
Del gráfico 6.5 se observa que para el total de asalariados la mejora distributiva se debe en mayor medida a una comprensión salarial en la parte superior de la distribución. Mientras que la brecha salarial entre p10-p50 se redujo alrededor del 18\%, la brecha entre los salarios de los percentiles 90 y 50 lo hizo en aproximadamente $24 \%$.

Gráfico 6.5. Tendencias de la desigualdad

Total asalariados - $2003-2013$

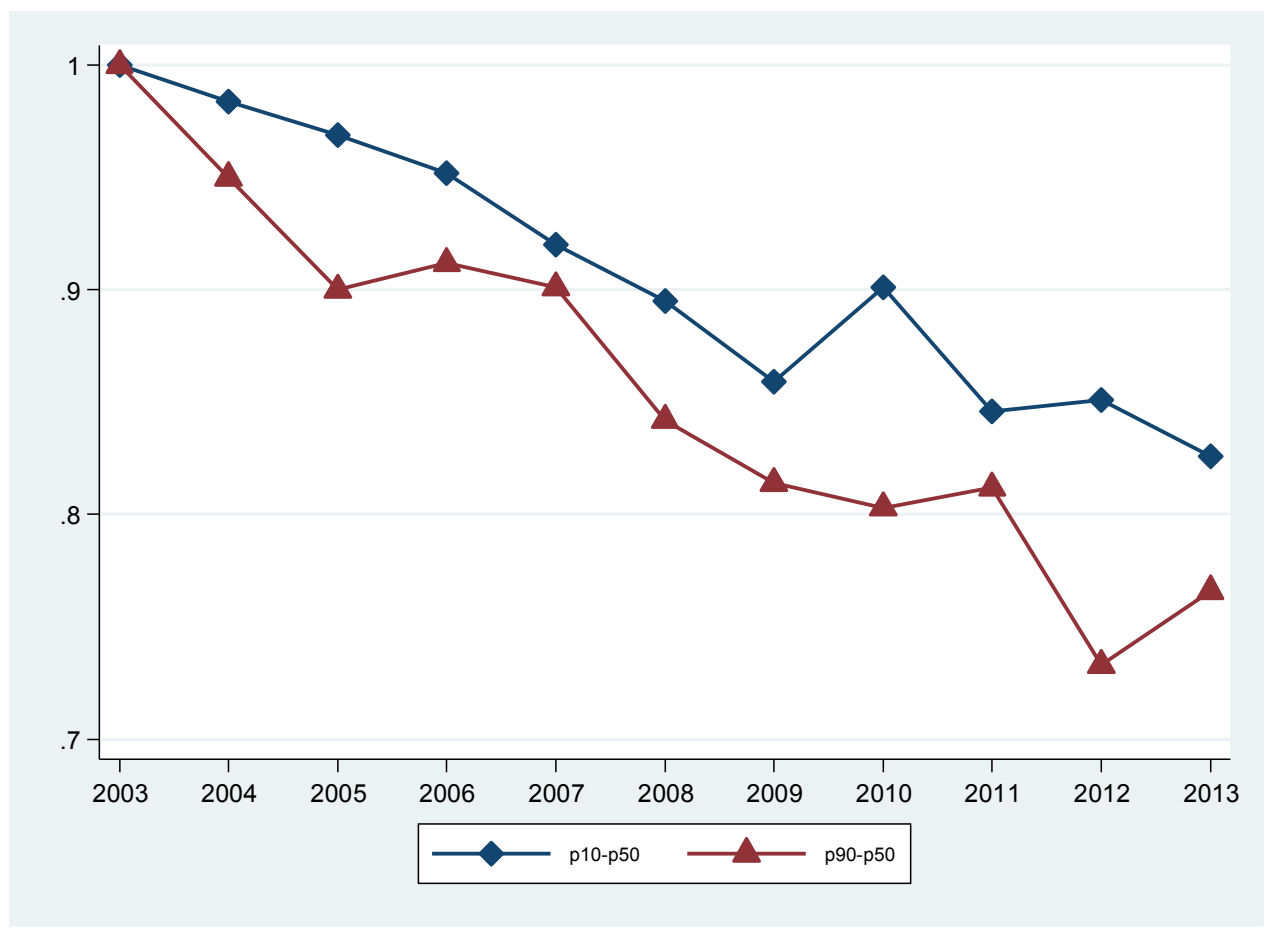

Fuente: INDEC. 4to trimestre de la EPHC.

El panorama se modifica sensiblemente cuando se considera a los asalariados formales (gráfico 6.6). Si bien la disminución de la desigualdad observada durante el período 2003 y 2013 se debió en mayor medida a la compresión en la parte superior de la distribución, la brecha se redujo $28 \%$ a lo largo del período (mientras que la brecha p10-p50 lo hizo en 15\%), durante los primeros años se observa una notable mejora en la parte inferior de la distribución. Entre 2003 y 2009 la brecha p10-p50 disminuyó en un 20\%.

Al considerar al grupo de asalariados informales, gráfico 6.7, se observa una vez más que la mejora distributiva evidencia durante el período 2003 - 2013 se debe en mayor medida a la mejora distributiva experimentada en la parte superior de la distribución. La brecha salarial entre p10-p50 se redujo alrededor del $12 \%$, en el total del período, mientras que la brecha entre los salarios de los percentiles 90 y 50 lo hizo en aproximadamente $22 \%$. 
Gráfico 6.6. Tendencias de la desigualdad

Asalariados formales - 2003 - 2013

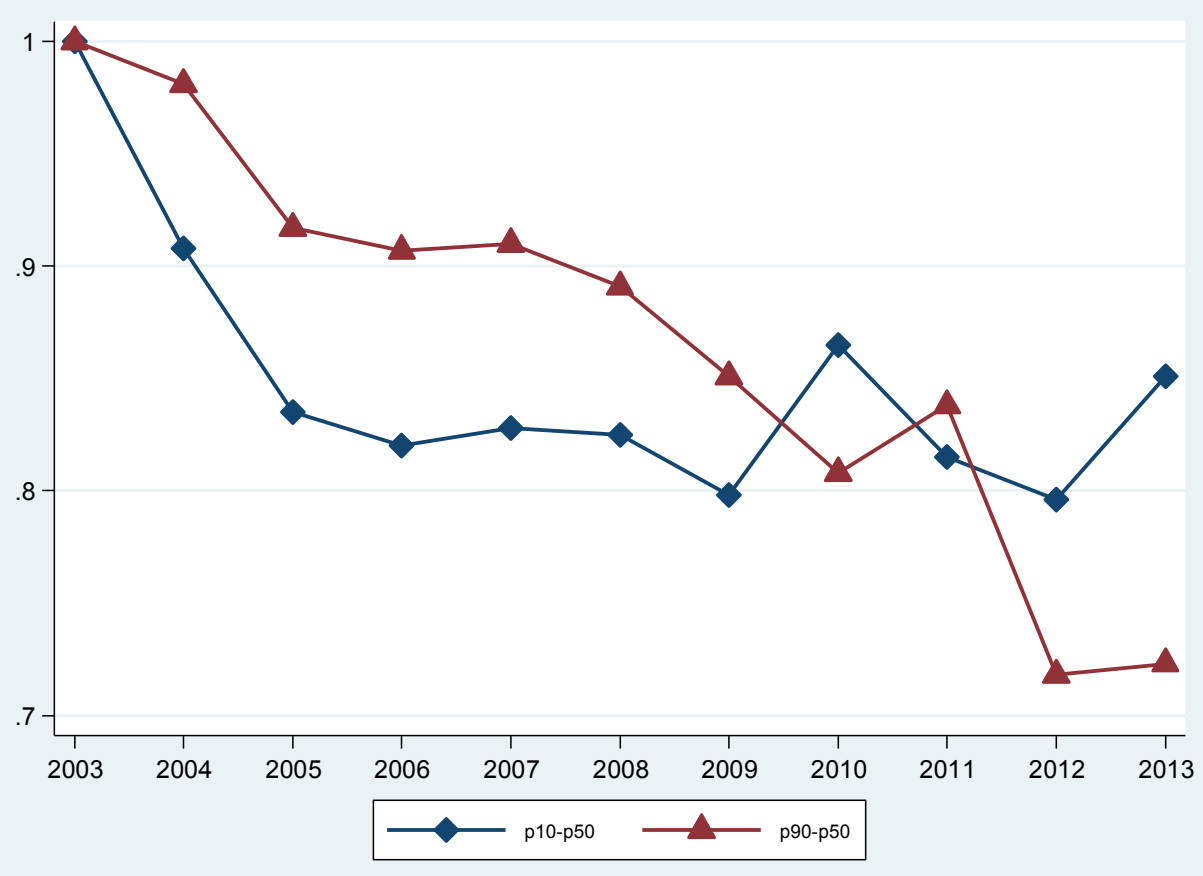

Fuente: INDEC. 4to trimestre de la EPHC.

Gráfico 6.7. Tendencias de la desigualdad

Asalariados informales - 2003 - 2013

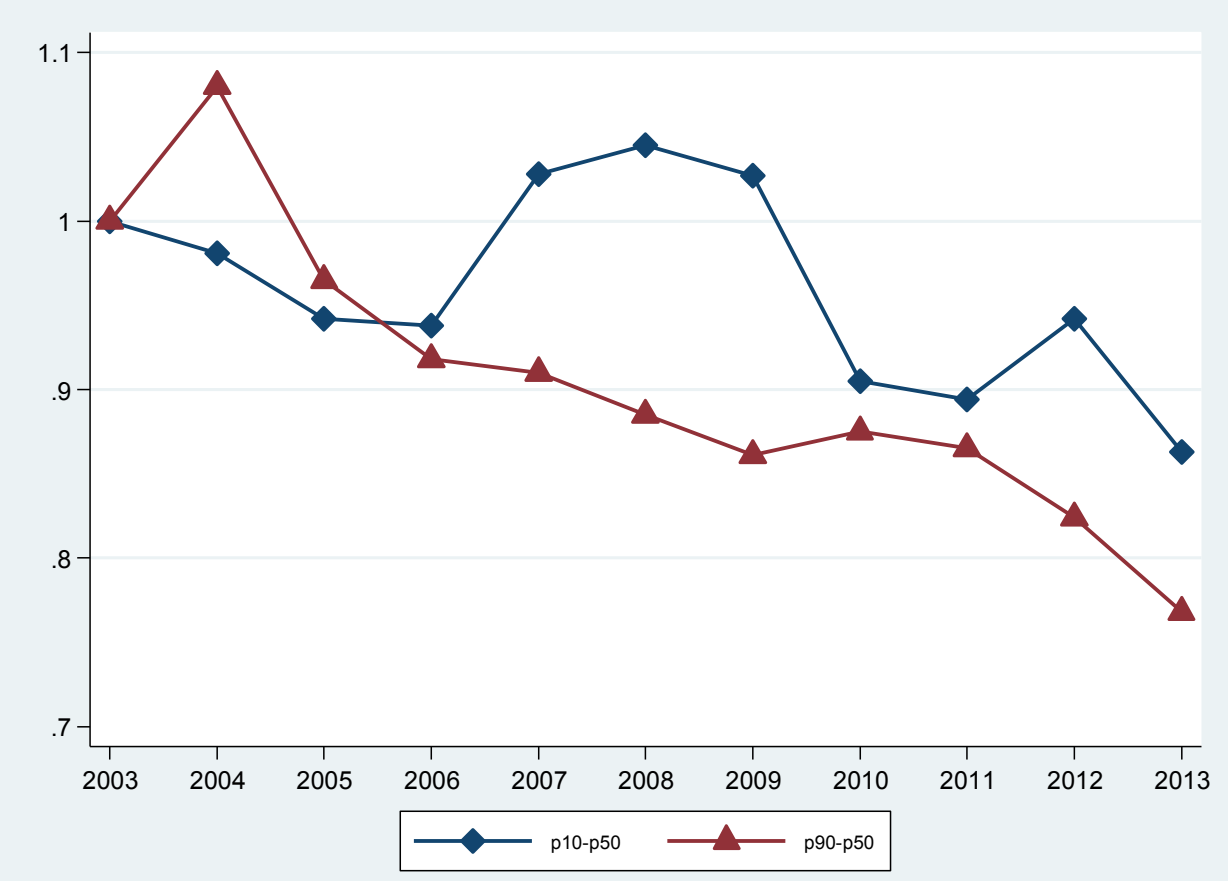

Fuente: INDEC. 4to trimestre de la EPHC. 
En resumen, a lo largo del período analizado se observa una mejora en la distribución salarial de todos los asalariados, aunque superior en el caso de los asalariados formales. Al analizar si la misma se relaciona con una mayor compresión salarial en la parte baja o alta de la distribución, los gráficos 6.3 a 6.7 indican que la brecha p90-p50 fue la que más se redujo tanto en el total de asalariados como para cada uno tipo de asalariados según su condición de formalidad. De todas maneras estas no dejan de ser conclusiones preliminares. En la segunda parte de la sección 7 se analizará el aporte del salario mínimo a la mejora distributiva y se volverá a este punto.

\section{Resultados}

En esta sección se procede al análisis formal del impacto del salario mínimo sobre la mejora en la distribución salarial evidenciada en Argentina durante la primera década de 2000. Para ello se utilizará la metodología descripta en la sección 5. Posteriormente, se retoman las tendencias de las brechas salariales respecto al percentil 50 y se descompone la caída en la desigualdad salarial observada, determinando cuánto de dicha variación se debe al efecto del salario mínimo y cuánto a otros factores.

\subsection{Efecto del salario mínimo}

La tabla 7.1 reporta las estimaciones de la ecuación (2), presentada en la sección 5, por variables instrumentales para el total de asalariados. Cada fila corresponde a una regresión diferente, donde la variable dependiente es la brecha entre el salario de cada decil con respecto al ingreso del percentil de referencia $(p=80)$, y la principal variable independiente es el salario mínimo efectivo, esto es, el salario mínimo relativo al salario del percentil 80 rezagado un año. Cada columna representa una especificación diferente. Se utilizó como ponderador el número de observaciones por aglomerado para cada período (trimestre-año). Entre corchetes se presentan los errores estándar con clústers por aglomerado ${ }^{15}$.

La columna 1 de la tabla 7.1 presenta las estimaciones del efecto del salario mínimo efectivo sobre la desigualdad salarial incluyendo efectos fijos temporales (trimestre-año) y a nivel aglomerado. La especificación 2 agrega controles demográficos que podrían estar correlacionadas con la evolución de la desigualdad. En particular, se controla por edad promedio, años de educación promedio y porcentaje de hombres. La especificación 3 incluye controles laborales: tasa de formalidad, porcentaje de individuos por sector de actividad, porcentaje de trabajadores en el sector público y la tasa de ocupación ${ }^{16}$, mientras que en la especificación 4 se controla adicionalmente por la proporción de individuos recibiendo planes de empleo. Todos los controles son a nivel aglomerado y varían por período.

\footnotetext{
${ }^{15}$ Las estimaciones por MCO se encuentran en las tablas A.4 a A.6 del apéndice, y consistentemente con lo que se predijo anteriormente, son sistemáticamente superior a las estimaciones por IV.

${ }^{16}$ La tasa de formalidad no se incluye como control cuando se estima el efecto del salario mínimo dentro de los asalariados formales e informales por separado.
} 
Tabla 7.1. Impacto del salario mínimo en las brechas salariales para el total de asalariados Estimaciones por variables instrumentales

\begin{tabular}{|c|c|c|c|c|}
\hline & [1] & [2] & [3] & [4] \\
\hline \multirow[t]{2}{*}{ p10-p80 } & $0.525^{* *}$ & $0.504^{* *}$ & $0.500 * *$ & $0.501^{* *}$ \\
\hline & [0.230] & [0.233] & {$[0.200]$} & {$[0.200]$} \\
\hline \multirow[t]{2}{*}{ p20-p80 } & $0.549 * *$ & $0.547^{* *}$ & $0.544 * *$ & $0.547^{* *}$ \\
\hline & [0.207] & [0.214] & [0.207] & [0.209] \\
\hline \multirow[t]{2}{*}{ p30-p80 } & $0.433^{* *}$ & $0.431 * *$ & $0.443 * *$ & $0.446 * *$ \\
\hline & [0.187] & [0.195] & [0.175] & [0.178] \\
\hline \multirow[t]{2}{*}{ p40-p80 } & $0.454 * * *$ & $0.448 * * *$ & $0.470 * * *$ & $0.473 * * *$ \\
\hline & [0.155] & [0.159] & [0.147] & [0.148] \\
\hline \multirow[t]{2}{*}{ p50-p80 } & $0.293 * *$ & $0.289 * *$ & $0.313^{* *}$ & $0.316 * *$ \\
\hline & [0.132] & [0.137] & [0.142] & [0.145] \\
\hline \multirow[t]{2}{*}{ p60-p80 } & $0.308^{* * *}$ & $0.309 * * *$ & $0.313^{* * *}$ & $0.313^{* * *}$ \\
\hline & [0.103] & [0.107] & [0.103] & [0.103] \\
\hline \multirow[t]{2}{*}{ p70-p80 } & $0.139 *$ & $0.141^{*}$ & $0.158^{*}$ & $0.160^{*}$ \\
\hline & [0.069] & [0.074] & [0.083] & [0.081] \\
\hline \multirow[t]{2}{*}{ p90-p80 } & -0.054 & -0.042 & -0.049 & -0.051 \\
\hline & [0.101] & [0.102] & [0.105] & [0.103] \\
\hline $\begin{array}{l}\text { Controles } \\
\text { demográficos }\end{array}$ & NO & SI & SI & SI \\
\hline $\begin{array}{l}\text { Controles } \\
\text { laborales }\end{array}$ & NO & NO & SI & SI \\
\hline $\begin{array}{l}\text { Control x plan } \\
\text { de empleo }\end{array}$ & NO & NO & NO & SI \\
\hline Observaciones & 1044 & 1044 & 1044 & 1044 \\
\hline
\end{tabular}

Nota: Cada entrada en la tabla se refiere al coeficiente de la regresión de las brechas sucesivas de cada decil respecto al ingreso del decil 8 en el salario mínimo efectivo. ${ }^{* * *} p<0.01, * * p<0.05, * p<0.1$; errores estándar entre corchetes, con clústers por aglomerado. En todas las especificaciones se incluyen efectos fijos por período (trimestre-año) y aglomerado. Controles demográficos: edad promedio, años de educación promedio y porcentaje de hombres. Controles laborales: tasa de formalidad, porcentaje de individuos por sector de actividad, porcentaje de trabajadores en el sector público y la tasa de ocupación. Control x plan de empleo: proporción de individuos recibiendo planes de empleo. Los controles demográficos, la tasa de formalidad y el porcentaje de individuos por sector de actividad se calcularon por aglomerado para los asalariados a tiempo completo, con ingresos positivos, de entre 16 y 60-65 años para las mujeres y hombres, respectivamente, excluidos los trabajadores del servicio doméstico, así como los beneficiarios de planes de empleo. El resto de los controles se calculó por período y aglomerado para la población entre 16 y 60-65 años, para las mujeres y hombres, respectivamente.

De la tabla 7.1 se observa un claro efecto igualador del salario mínimo sobre la distribución de salarios. De acuerdo a la especificación 1, en promedio, un aumento de 10 p.p. en el salario mínimo relativo al ingreso del percentil 80 se asocia con un aumento, estadísticamente significativo, de aproximadamente 5 p.p. del ingreso del percentil 10 respecto al ingreso del percentil 80, y consecuentemente una disminución de la brecha salarial entre ambos percentiles. Los coeficientes tienden a ser más pequeños para los deciles más altos (con excepción de las brechas entre los percentiles 20-80 y 30-80), y estadísticamente significativas hasta el percentil 70 . Al pasar del modelo 1 a la especificación 2 se observa que, aún controlando por características demográficas los resultados se mantienen tanto cualitativa como cuantitativamente. El efecto del 
salario mínimo efectivo en las brechas salariales en términos cuantitativos es prácticamente el mismo en las 2 especificaciones.

La inclusión de controles laborales y del porcentaje de individuos recibiendo planes de empleo tampoco cambian sustancialmente los resultados. En la especificación con controles laborales y con control por plan de empleo, en promedio, un aumento de 10 p.p. del salario mínimo respecto a los ingresos de percentil 80 se asocia a un aumento, estadísticamente significativo, de 5 p.p. de los ingresos del percentil 10 en relación a los del percentil 80.

Tabla 7.2. Impacto del salario mínimo en las brechas salariales para los asalariados formales Estimaciones por variables instrumentales

\begin{tabular}{|c|c|c|c|c|}
\hline & [1] & [2] & [3] & [4] \\
\hline \multirow[t]{2}{*}{ p10-p80 } & $0.494^{*}$ & $0.474^{*}$ & $0.504 *$ & $0.502^{*}$ \\
\hline & {$[0.256]$} & {$[0.269]$} & {$[0.286]$} & {$[0.287]$} \\
\hline \multirow[t]{2}{*}{ p20-p80 } & $0.663^{* * *}$ & $0.658 * * *$ & $0.691 * * *$ & $0.693 * * *$ \\
\hline & [0.208] & {$[0.226]$} & {$[0.242]$} & {$[0.237]$} \\
\hline \multirow[t]{2}{*}{ p30-p80 } & $0.471 * *$ & $0.459 * *$ & $0.503 * *$ & $0.502^{* *}$ \\
\hline & [0.196] & {$[0.207]$} & {$[0.214]$} & {$[0.215]$} \\
\hline \multirow[t]{2}{*}{ p40-p80 } & $0.409 * * *$ & $0.399 * *$ & $0.432 * *$ & $0.431 * *$ \\
\hline & [0.148] & [0.156] & [0.161] & {$[0.162]$} \\
\hline \multirow[t]{2}{*}{ p50-p80 } & $0.318 * *$ & $0.310 * *$ & $0.327 * *$ & $0.327 * *$ \\
\hline & [0.125] & [0.130] & {$[0.134]$} & [0.135] \\
\hline \multirow[t]{2}{*}{ p60-p80 } & 0.143 & 0.122 & 0.126 & 0.124 \\
\hline & [0.120] & [0.134] & {$[0.142]$} & {$[0.142]$} \\
\hline \multirow[t]{2}{*}{ p70-p80 } & 0.025 & 0.007 & 0.007 & 0.004 \\
\hline & [0.102] & [0.114] & [0.121] & {$[0.118]$} \\
\hline \multirow[t]{2}{*}{ p90-p80 } & -0.153 & -0.157 & -0.174 & -0.170 \\
\hline & [0.154] & [0.163] & {$[0.166]$} & {$[0.164]$} \\
\hline $\begin{array}{l}\text { Controles } \\
\text { demográficos }\end{array}$ & NO & $\mathrm{SI}$ & SI & SI \\
\hline $\begin{array}{l}\text { Controles } \\
\text { laborales }\end{array}$ & NO & NO & $\mathrm{SI}$ & $\mathrm{SI}$ \\
\hline $\begin{array}{l}\text { Control x plan } \\
\text { de empleo }\end{array}$ & NO & NO & NO & SI \\
\hline Observaciones & 1044 & 1044 & 1044 & 1044 \\
\hline
\end{tabular}

Nota: Cada entrada en la tabla se refiere al coeficiente de la regresión de las brechas sucesivas de cada decil respecto al ingreso del decil 8 en el salario mínimo efectivo. ${ }^{* * *} p<0.01, * * p<0.05, * p<0.1$; errores estándar entre corchetes, con clústers por aglomerado. En todas las especificaciones se incluyen efectos fijos por período (trimestre-año) y aglomerado. Controles demográficos: edad promedio, años de educación promedio y porcentaje de hombres. Controles laborales: porcentaje de individuos por sector de actividad, porcentaje de trabajadores en el sector público y la tasa de ocupación. Control x plan de empleo: proporción de individuos recibiendo planes de empleo. Los controles demográficos y el porcentaje de individuos por sector de actividad se calcularon por aglomerado para los asalariados a tiempo completo, con ingresos positivos, de entre 16 y 60-65 años para las mujeres y hombres, respectivamente, excluidos los trabajadores del servicio doméstico, así como los beneficiarios de planes de empleo. El resto de los controles se calculó por período y aglomerado para la población entre 16 y 60-65 años, para las mujeres y hombres, respectivamente.

Los resultados presentados anteriormente corresponden al total de trabajadores asalariados. La tabla 7.2 presenta los resultados al estimar el impacto del salario mínimo sobre la dispersión 
salarial para los asalariados formales a tiempo completo, es decir, aquellos que por ley deberían beneficiarse ante cambios en el valor del mismo.

De acuerdo a la especificación 4 de la tabla 7.2, un aumento de 10 p.p. del salario mínimo relativo al ingreso del percentil 80 conlleva un incremento, estadísticamente significativo, de aproximadamente 5 p.p. del ingreso del percentil 10 respecto al ingreso del percentil 80 . En el caso de los asalariados formales el impacto del salario mínimo es estadísticamente significativo hasta el percentil 50.

Tabla 7.3. Impacto del salario mínimo en las brechas salariales para los asalariados informales Estimaciones por variables instrumentales

\begin{tabular}{|c|c|c|c|c|}
\hline & [1] & [2] & [3] & [4] \\
\hline \multirow[t]{2}{*}{ p10-p80 } & 0.609 & 0.578 & 0.463 & 0.438 \\
\hline & [0.434] & {$[0.425]$} & [0.410] & [0.434] \\
\hline \multirow[t]{2}{*}{ p20-p80 } & 0.334 & 0.297 & 0.278 & 0.255 \\
\hline & [0.321] & {$[0.328]$} & {$[0.338]$} & [0.357] \\
\hline \multirow[t]{2}{*}{ p30-p80 } & 0.145 & 0.130 & 0.105 & 0.072 \\
\hline & [0.293] & [0.292] & [0.307] & [0.329] \\
\hline \multirow[t]{2}{*}{ p40-p80 } & 0.307 & 0.307 & 0.303 & 0.271 \\
\hline & [0.231] & [0.239] & {$[0.247]$} & [0.259] \\
\hline \multirow[t]{2}{*}{ p50-p80 } & 0.259 & 0.237 & 0.226 & 0.205 \\
\hline & [0.208] & {$[0.217]$} & {$[0.214]$} & [0.225] \\
\hline \multirow[t]{2}{*}{ p60-p80 } & -0.018 & -0.009 & -0.011 & -0.028 \\
\hline & {$[0.216]$} & {$[0.220]$} & {$[0.223]$} & [0.240] \\
\hline \multirow[t]{2}{*}{ p70-p80 } & 0.104 & 0.113 & 0.108 & 0.094 \\
\hline & [0.190] & [0.196] & {$[0.202]$} & [0.214] \\
\hline \multirow[t]{2}{*}{ p90-p80 } & -0.125 & -0.115 & -0.130 & -0.139 \\
\hline & {$[0.240]$} & {$[0.233]$} & {$[0.245]$} & [0.264] \\
\hline $\begin{array}{l}\text { Controles } \\
\text { demográficos }\end{array}$ & NO & SI & SI & SI \\
\hline $\begin{array}{l}\text { Controles } \\
\text { laborales }\end{array}$ & NO & NO & SI & SI \\
\hline $\begin{array}{l}\text { Control x plan } \\
\text { de empleo }\end{array}$ & NO & NO & NO & SI \\
\hline Observaciones & 1044 & 1044 & 1044 & 1044 \\
\hline
\end{tabular}

Nota: Cada entrada en la tabla se refiere al coeficiente de la regresión de las brechas sucesivas de cada decil respecto al ingreso del decil 8 en el salario mínimo efectivo. ${ }^{* * *} p<0.01, * * p<0.05, * p<0.1$; errores estándar entre corchetes, con clústers por aglomerado. En todas las especificaciones se incluyen efectos fijos por período (trimestre-año) y aglomerado. Controles demográficos: edad promedio, años de educación promedio y porcentaje de hombres. Controles laborales: porcentaje de individuos por sector de actividad, porcentaje de trabajadores en el sector público y la tasa de ocupación. Control x plan de empleo: proporción de individuos recibiendo planes de empleo. Los controles demográficos y el porcentaje de individuos por sector de actividad se calcularon por aglomerado para los asalariados a tiempo completo, con ingresos positivos, de entre 16 y 60-65 años para las mujeres y hombres, respectivamente, excluidos los trabajadores del servicio doméstico, así como los beneficiarios de planes de empleo. El resto de los controles se calculó por período y aglomerado para la población entre 16 y 60-65 años, para las mujeres y hombres, respectivamente. 
Al estudiar el posible efecto del salario mínimo sobre los trabajadores informales (tabla 7.3) no se encuentran resultados estadísticamente significativos para ninguna de las especificaciones. Los resultados obtenidos van en la misma línea de lo hallado por Maurizio (2014b) quien sostiene que "en Argentina la brecha entre los trabajadores formales e informales en la parte inferior de la distribución se amplió entre 2003 y 2011, mientras que lo contrario ocurrió en la cola superior". La autora sostiene que este resultado puede hallarse si el salario mínimo es operativo solamente, o al menos en su mayoría, para los trabajadores formales.

\subsection{Descomposición del cambio en la desigualdad salarial: la contribución del salario mínimo}

En esta última sub-sección, se estima cuál es el impacto del salario mínimo real, entendido como la diferencia entre el valor del salario mínimo y el salario mediano (todo en logaritmo), en el total de la caída en la desigualdad salarial observada. Para ello se descompone el cambio en esta última entre aquella variación producto del aumento en el salario mínimo y los cambios como consecuencia de otros factores, para el período comprendido entre 2004 y $2013^{17}$.

Para realizar tal descomposición se estiman las tendencias de las brechas observadas entre los salarios de cada decil del ingreso y el ingreso mediano, así como las tendencias de los cambios producto del salario mínimo. Las variaciones de la desigualdad como consecuencia de otros factores se obtienen por diferencia. Todo se estimó siguiendo la especificación 4 de las tablas 7.1 y 7.2 de la sección anterior. Adicionalmente, dado que el modelo predice un efecto del salario mínimo sobre los salarios del total de asalariados y de los asalariados formales, las estimaciones se realizaron para estos 2 grupos.

Las tablas 7.4 y 7.5 presentan los resultados para el total de asalariados y los asalariados formales, respectivamente. En ambas tablas, la primera columna resume el cambio observado, la columna 2 corresponde al cambio en la distribución de salarios como consecuencia de variaciones en el salario mínimo, mientras que la columna 3 resume el efecto de otros factores sobre la distribución. Las estimaciones de la columna 2 se refieren a la tendencia lineal de los coeficientes, con errores estándar con clústers por año. Todas las series están estandarizadas al valor del año 2004.

Una mejora distributiva en la cola inferior de la distribución (brechas p10-p50 a p40-p50), entendida como una mayor participación de los ingresos de los percentiles más bajos respecto al ingreso del percentil 50, hará que la brecha negativa entre los ingresos de ambos percentiles sea menos negativa, lo que implicará un coeficiente positivo. Por el contrario, un aumento de la desigualdad entre dichos percentiles hará mayor en términos absolutos el valor de la brecha, siendo negativo el valor del coeficiente respecto al año base.

\footnotetext{
${ }^{17}$ Se realiza desde 2004 debido a que la instrumentación del salario mínimo se realiza con el logaritmo del salario rezagado un año, y dado que la EPH comenzó su relevamiento continuo a partir del 3er trimestre de 2003, el instrumento puede construirse a partir del 3er trimestre de 2004.
} 
Al considerar los cambios distributivos en la cola superior, las brechas entre los ingresos de los percentiles p60 a p90 respecto al ingreso mediano son positivas, de modo que una mejora distributiva, entendida como una mayor participación del ingreso del percentil 50 respecto al ingreso de los percentiles superiores, implicará una brecha menor, por lo que el coeficiente de la misma respecto al año 2004 será negativa. Contrariamente, un agudizamiento de la brecha conllevará un coeficiente positivo respecto al año base.

Por lo tanto, un coeficiente positivo (negativo) para las brechas p10-p50 a p40-p50 estará relacionado con una disminución (aumento) de la desigualdad salarial, mientras que sucede lo contrario para las brechas p60-p50 a p90-p50, un coeficiente positivo (negativo) para las brechas p60-p50 a p90-p50 estará relacionado con una aumento (disminución) de la desigualdad salarial.

Tabla 7.4. Tendencias estimadas en los diferenciales de ingresos y la contribución de los salarios mínimos - Total asalariados - 2004-2013

\begin{tabular}{lccc}
\hline & $\begin{array}{c}\text { Brecha } \\
\text { observada }\end{array}$ & $\begin{array}{c}\text { Cambio } \\
\text { por SM }\end{array}$ & $\begin{array}{c}\text { Cambio } \\
\text { residual }\end{array}$ \\
\hline p10-p50 & $0.014^{* * *}$ & $0.003^{* * *}$ & $0.012^{* * *}$ \\
& $(0.000)$ & $(0.000)$ & $(0.000)$ \\
p20-p50 & $0.009^{* * *}$ & $-0.001^{* * *}$ & $0.010^{* * *}$ \\
& $(0.000)$ & $(0.000)$ & $(0.000)$ \\
p30-p50 & $0.006^{* * *}$ & $0.004^{* * *}$ & $0.002^{* * *}$ \\
& $(0.000)$ & $(0.000)$ & $(0.000)$ \\
p40-p50 & $0.004^{* * *}$ & $0.001^{* * *}$ & $0.003^{* * *}$ \\
& $(0.000)$ & $(0.000)$ & $(0.000)$ \\
p60-p50 & $-0.002^{* * *}$ & $-0.002^{* * *}$ & 0.000 \\
& $(0.000)$ & $(0.000)$ & $(0.000)$ \\
p70-p50 & $-0.005^{* * *}$ & $0.001^{* * *}$ & $-0.006^{* * *}$ \\
& $(0.000)$ & $(0.000)$ & $(0.000)$ \\
p80-p50 & $-0.011^{* * *}$ & $-0.001^{* * *}$ & $-0.010^{* * *}$ \\
& $(0.000)$ & $(0.000)$ & $(0.000)$ \\
p90-p50 & $-0.019^{* * *}$ & $-0.001^{* * *}$ & $-0.018^{* * *}$ \\
& $(0.000)$ & $(0.000)$ & $(0.000)$ \\
\hline
\end{tabular}

Nota: La tabla muestra el cambio anual estimado de las brechas de cada decil del ingreso relativo al ingreso mediano. La columna 2 reporta los cambios en la desigualdad producto del aumento en el valor real del salario mínimo basado en las estimaciones de la especificación 4 de las tablas 7.1 y 7.2. La columna 3 reporta el cambio residual. Errores estándar entre paréntesis, con clúster por año. Se estimó utilizando información del 4to trimestre de la EPHC.

De la tabla 7.4 se observa que todas las brechas salariales disminuyeron a lo largo del período y tal como se predijo en la sección $6.3^{18}$ lo hizo en mayor medida en la cola superior de la distribución. Mientras que la brecha salarial entre los percentiles 10 y 50 disminuyó, en promedio, 1.4 p.p. por año, la brecha 90-50 lo hizo en 1.9 p.p.. De la brecha observada, la columna 2 nos indica que el

\footnotetext{
${ }^{18}$ A diferencia de lo estimado en esta sección, las estimaciones de las tendencias en la sección 6.3 se hicieron incluyendo en las estimaciones sólo dummies por año y aglomerado.
} 
aumento del salario mínimo real es responsable de una disminución de 0.3 p.p por año en la brecha p10-p50, mientras que otros factores explican una caída de 1.2 p.p. por año. Todos los resultados son estadísticamente significativos.

En cuanto a los efectos distributivos del salario mínimo real a lo largo de toda la distribución salarial, los mismos resultan ambiguos, igualadores en la mayoría de los casos, pero con efectos desigualadores para las brechas p20-p50 y p70-p50, siempre estadísticamente significativos.

Las estimaciones correspondientes a los asalariados formales se presentan en la tabla 7.5. De acuerdo a la columna 1, todas las brechas salariales observadas disminuyeron a lo largo del período, en mayor medida en la cola superior de la distribución, tal como se predijo en la sección 6.3. Mientras que la brecha entre el percentil 90 y el 50 se redujo en promedio en 1.9 p.p. por año, la brecha entre los percentiles 10 y 50 lo hizo en tan sólo 0.1 p.p. por año. Sin embargo, esta pequeña mejora observada en la cola inferior de la distribución se relaciona con factores distintos al salario mínimo. La recuperación del valor real del mismo se asocia con una caída, estadísticamente significativa, de la desigualdad de 0.5 p.p. por año, siendo otros los factores operantes que contrarrestaron el efecto del salario mínimo.

Tabla 7.5. Tendencias estimadas en los diferenciales de ingresos y la contribución de los salarios mínimos - Asalariados formales - 2004-2013

\begin{tabular}{lccc}
\hline & $\begin{array}{c}\text { Brecha } \\
\text { observada }\end{array}$ & $\begin{array}{c}\text { Cambio } \\
\text { por SM }\end{array}$ & $\begin{array}{c}\text { Cambio } \\
\text { residual }\end{array}$ \\
\hline p10-p50 & $0.001^{* * *}$ & $0.005^{* * *}$ & $-0.004^{* * *}$ \\
& $(0.001)$ & $(0.001)$ & $(0.001)$ \\
p20-p50 & $0.002^{* * *}$ & $-0.001^{* * *}$ & $0.002^{* * *}$ \\
p30-p50 & $(0.001)$ & $(0.000)$ & $(0.000)$ \\
& $0.003^{* * *}$ & $0.003^{* * *}$ & 0.000 \\
p40-p50 & $(0.000)$ & $(0.000)$ & $(0.001)$ \\
& $0.001^{* * *}$ & $-0.002^{* * *}$ & $0.004^{* * *}$ \\
p60-p50 & $(0.000)$ & $(0.000)$ & $(0.000)$ \\
& $-0.002^{* * *}$ & $-0.001^{* * *}$ & $-0.002^{* * *}$ \\
p70-p50 & $(0.000)$ & $(0.000)$ & $(0.000)$ \\
& $-0.006^{* * *}$ & $0.001^{* * *}$ & $-0.007^{* * *}$ \\
p80-p50 & $(0.000)$ & $(0.000)$ & $(0.000)$ \\
& $-0.011^{* * *}$ & $-0.000^{* * *}$ & $-0.010^{* * *}$ \\
p90-p50 & $(0.000)$ & $(0.000)$ & $(0.000)$ \\
& $-0.019^{* * *}$ & $0.001^{* * *}$ & $-0.020^{* * *}$ \\
\hline
\end{tabular}

Nota: La tabla muestra el cambio anual estimado de las brechas de cada decil del ingreso relativo al ingreso mediano. La columna 2 reporta los cambios en la desigualdad producto del aumento en el valor real del salario mínimo basado en las estimaciones de la especificación 4 de las tablas 7.1 y 7.2. La columna 3 reporta el cambio residual. Errores estándar entre paréntesis, con clúster por año. Se estimó utilizando información del 4to trimestre de la EPHC. 
En resumen, el aumento del salario mínimo real a lo largo del período bajo estudio fue un factor determinante de la caída de la desigualdad salarial a lo largo de toda la distribución, con algunas excepciones, tanto para el total de asalariados como para el conjunto de asalariados formales. Al concentrarnos en la parte más baja de la distribución, recordemos que la implementación de un salario mínimo tiene por objeto fijar un umbral a los ingresos de los asalariados más vulnerables, el impacto igualador fue mayor dentro del grupo de asalariados formales, que para el total de asalariados, la brecha de ingresos observada p10-p50 cayó 0.5 p.p. por año, para los asalariados registrados, y 0.3 p.p. para el total, producto de la recuperación del salario mínimo real.

\section{Comentarios finales}

Desde comienzos de los años 2000 Argentina experimentó una significativa disminución de la desigualdad de ingreso, explicada en mayor medida por una mejora distributiva de los ingresos laborales. Aún cuando existe consenso en cuanto a la mayor importancia de los ingresos laborales en la caída de la desigualdad (Bertranou y Maurizio, 2011; Trujillo y Villafañe, 2011; Keifman y Maurizio, 2012; Alejo et al. 2013; Azevedo et al., 2013a) la literatura que estudia los factores detrás de dicha mejora se ha focalizado en el rol de los retornos a la educación.

En este contexto el presente trabajo estudia el impacto del aumento del salario mínimo real en la mejora salarial, focalizándose en los asalariados a tiempo completo. Para ello se utilizó la metodología propuesta por Lee (1999). En primer lugar se estimó el impacto del aumento del salario mínimo efectivo, entendido como la diferencia entre el valor del salario mínimo y el ingreso de un percentil de referencia rezagado un período sobre la dispersión salarial, medida esta última a través de las brechas sucesivas del salario de cada percentil del ingreso en relación al ingreso del percentil de referencia. Los resultados sugieren un efecto igualador del aumento del salario mínimo efectivo para el total de asalariados y para los asalariados formales, no así para los asalariados no registrados. Los resultados son robustos a diferentes especificaciones. Un aumento de 10 p.p. en el salario mínimo relativo al ingreso del percentil 80 se asocia con un aumento, estadísticamente significativo, de aproximadamente 5 p.p. del ingreso del percentil 10 respecto al ingreso del percentil 80, y consecuentemente una disminución de la brecha de ingresos entre ambos percentiles para el total de asalariados y para los asalariados formales.

Adicionalmente se descompuso la caída observada de la desigualdad salarial entre la variación aportada por el aumento del salario mínimo real y aquella relacionada con otros factores. Los resultados sugieren un efecto igualador a lo largo de casi toda la distribución salarial, especialmente fuerte en la cola inferior de la distribución para el caso de los asalariados formales. En este sentido, el aumento del valor del salario mínimo explica una caída, en promedio, de 0.5 p.p. por año, para los trabajadores formales, y de 0.3 p.p. para el total de asalariados.

\section{Referencias}

Abowd J., F. Kramarz y D. Margolis (1999). Minimum Wages and Employment in France and the United States, NBER Working Paper 6996. 
Akerlof G. y J. Yellen (1990). The Fair Wage-Effort Hypothesis and Unemployment, Quarterly Journal of Economics, vol. 105 (issue 2), pp. 255-283.

Alaniz E., T. Gindling y K. Terrell (2011). The impact of minimum wages on wages, work and poverty in Nicaragua. Labour Economics, vol. 18, sup(1), pp. S45-S59.

Alejo, J. (2012). Educación y Desigualdad: una metodología de descomposición basada en dos interpretaciones de la ecuación de Mincer. Evidencia para Argentina, Anales de la XLVII Reunión Anual de la Asociación Argentina de Economía Política, Trelew, Argentina.

Alejo J., M. Bérgolo y F. Carbajal (2013). Las Transferencias Públicas y su Impacto Distributivo: La Experiencia de los Países del Cono sur en la década de 2000, CEDLAS Working Paper N. 141, CEDLAS, UNLP.

Altimir O., L. Beccaria y M. González Rozada (2002). La distribución del ingreso en Argentina, 19742000. Revista de la CEPAL 78: 55-86.

Alvaredo F. y L. Gasparini (2013). Recent trends in inequality and poverty in developing countries, CEDLAS Working Paper N. 151, CEDLAS, UNLP.

Amarante V., M. Colafranceschi y A. Vigorito. (2011). Uruguay's income inequality and political regimes during 1981-2010 (No. 2011/94). WIDER Working Paper.

Autor D., A. Manning y C. Smith (2010). The Role of the Minimum Wage in the Evolution of US Wage Inequality over Three Decades: A Modest Re-Assessment, NBER Working Paper 16533.

Azevedo J., G. Inchauste y V. Sanfelice (2013a). Decomposing the recent inequality decline in Latin America, World Bank Policy Research Working Paper, (6715).

Azevedo J., M. Dávalos, C. Diaz-Bonilla, B. Atuesta y R. Castañeda (2013b). Fifteen years of inequality in Latin America: how have labor markets helped?, World Bank Policy Research Working Paper, (6384).

Battistón D., C. García-Domench y L. Gasparini (2014). Could an increase in education raise income inequality?: Evidence for Latin America, Latin American Journal of Economics, vol. 51 (issue 1), pp. 1-39.

Beccaria L. y P. Gain (2003). Regulaciones laborales en Argentina; evaluación y propuestas. Fundación OSDE.

Beccaria L. y R. Maurizio (2010). Explorando un enfoque de regulaciones laborales y protección social para América Latina. Revista de Economía Política de Buenos Aires (7 y 8).

Beccaria L. y R. Maurizio (2012). Reversión y continuidades bajo dos regímenes macroeconómicos diferentes. Mercado de trabajo e ingresos en argentina 1990-2010. Desarrollo Económico: Revista de Ciencias Sociales, 205-228.

Beccaria L., R. Maurizio y G. Vázquez (2014). Recent changes in wage inequality in Argentina. The role of labor formalization and other factors. MPRA Paper 56701, University Library of Munich, Germany. 
Bernstein J. y J. Schmitt (1998). Making Work Pay: The Impact of the 1996-97 Minimum Wage Increase, Washington, D.C.: Economic Policy Institute.

Bertranou F. y R. Maurizio (2011). The role of labour market and social protection in reducing inequality and eradicating poverty in Latin America. MPRA Paper 39843, University Library of Munich, Germany.

Betcherman, G. (2014). What Do We Know about Their Impacts in Developing Countries?, World Bank Policy Research Working Paper, (6819).

Borjas, G. (1980). The Relationship between Wages and Weekly Hours of Work: The Role of Division Bias, Journal of Human Resources, Vol. 15, No. 3, pp. 409-423

Bosch M. y M. Manacorda (2010). Minimum Wages and Earnings Inequality in Urban Mexico, American Economic Journal: Applied Economics 2, pp. 128-49.

Bosch M. y C. González Velosa (2013). The Role of Minimum Wages on the Decline of Earnings Inequality in Brazil. Trabajo presentado en la XX Meetings of the LACEA/ IADB/ WB/ UNDP Research Network on Inequality and Poverty (NIP), Washington DC.

Bronstein, A. (1993). La regulación del salario mínimo: normas internacionales y legislación nacional. Jornadas conmemorativas del cincuentenario de la Ley de creación de los consejos de salarios en el Uruguay. Montevideo: Universidad de la República.

Brown, C. (1999). Minimum wages, employment, and the distribution of income, en O. Ashenfelter y Card D. (ed.) Handbook of Labor Economics, vol. 3, Part B, pp 2101-2163.

Brown C., C. Gilroy y A. Kohen (1982). The effect of minimum wage on employment and unemployment, Journal of Economic Literature, 20, pp. 487-528.

Card, D. (1992). Do Minimum Wages Reduce Employment? A Case Study of California, 1987-89, Industrial and Labor Relations Review, vol. 4, No. 1, pp.38-54

Card D. y A. Krueger (1994). Minimum Wages and Employment: A Case Study of the Fast-Food Industry in New Jersey and Pennsylvania, American Economic Review, vol. 84(4), pp. 772-793.

Cruces G. y L. Gasparini (2013). Políticas sociales para la reducción de la desigualdad y la pobreza en América Latina y el Caribe. Diagnóstico, propuesta y proyecciones en base a la experiencia reciente, CEDLAS Working Paper N. 151, CEDLAS, UNLP.

Cornia, A. (2012). Inequality Trends and their Determinants: Latin America over 1990-2011, WIDER Working Paper N²012/09.

Dickens R., S. Machin y A. Manning (1999). The Effects of Minimum Wages on Employment: Theory and Evidence from Britain, Journal of Labor Economics, vol. 17(1), pp. 1-22.

Dickens R. y A. Manning (2004). Has the national minimum wage reduced UK wage inequality?, Journal of the Royal Statistical Society: Series A (Statistics in Society), 167(4), 613-626

DiNardo N., M. Fortin y T. Lemieux (1996). Labor Market Institutions and the Distribution of Wages, 1973-1992: A Semiparametric Approach, Econometrica, 64(5): 1001-1044. 
Dolado J., F. Kramarz, S. Machin, A. Manning, D. Margolis y C. Teulings (1996). The economic impact of minimum wages in Europe, Economic Policy, 23, 317-372.

Fajnzylber, P. (2001). Minimum Wage Effects Throughout the Wage Distribution: Evidence from Brazil's Formal and Informal Sectors, Department of Economics and CEDEPLAR, Universidade Federal de Minas Gerais, Belo Horizonte, Brazil.

Fortin N. y T. Lemieux (1997). Institutional changes and rising wage inequality: is there a linkage?, Journal of Economic Perspectives, vol. 11(2), pp. 75-96.

Gasparini L. y G. Cruces (2008). Una distribución en movimiento: El caso de Argentina, CEDLAS Working Paper N. 78, CEDLAS, UNLP.

Gasparini L., G. Cruces, L. Tornarolli y M. Marchionni (2009). A turning point? Recent developments on inequality in Latin America and the Caribbean, CEDLAS Working Paper N. 81, CEDLAS, UNLP.

Gasparini L., G. Cruces, y L. Tornarolli (2011a). Recent Trends in Income Inequality in Latin America, Economia 10(2), pp. 147-201.

Gasparini L., S. Galiani, G. Cruces y P. Acosta (2011b). Educational upgrading and returns to skills in Latin America: Evidence from a supply-demand framework, 1990-2010, IZA Discussion Paper 6244 and Policy Research Working Paper WPS 5921, the World Bank.

Gasparini L. y N. Lustig (2011). The rise and fall of income inequality in Latin America, En Ocampo, J.A. y Ros J., eds., The Oxford Handbook of Latin American Economics. Oxford: Oxford University Press.

Gindling T. y K. Terrell (2005). The Effect of Minimum Wages on Actual wages in the formal and informal sectors of Costa Rica, World Development 33(11), 1905-1921

Gindling T. y K. Terrell (2007). Minimum Wages and the Welfare of Workers in Honduras, IZA Discussion Paper 2892.

Gindling T., N. Mossaad y J. Trejos (2013). Las consecuencias del aumento en la observación del salario mínimo legal en Costa Rica: una evaluación del impacto de la Campaña Nacional de salarios mínimos, Instituto de Investigaciones en Ciencias Económicas (IICE), Universidad de Costa Rica.

Grau N. y O. Landerretche (2011). The labor impact of minimum wages: a method for estimating the effect in emerging economies using chilean panel data, Serie Documentos de Trabajo 239, Departamento de Economía, Universidad de Chile.

Groisman, F. (2012). Salario mínimo y empleo en Argentina, Revista de Economía Política de Buenos Aires, vol. 11, UBA pp. 9-47.

Holmlund, B. (2013). What Do Labor Market Institutions Do?, IZA Discussion Paper 7809.

Katz L. y A. Krueger (1992). The Effect of the Minimum Wage in the Fast Food Industry, Industrial and Labor Relations Review 46, 6-21.

Keifman S. y R. Maurizio (2012). Changes in Labour Market Conditions and Policies. Their Impact on Wage Inequality during the Last Decade, (No. 2012/14). WIDER Working Paper. 
Kim T. y L. Taylor (1995). The Employment Effect in Retail Trade of California's1988 Minimum Wage Increase, Journal of Business and Economic Statistics, 13(2), pp. 175-182.

Kostzer, D. (2006). Argentina: La recuperación del salario mínimo como herramienta de política de ingresos. En Marinakis, A. y J. Velasco (Eds.): ¿Para qué sirve el salario mínimo? Elementos para su determinación en los países del Cono Sur, pp. 35-104. Santiago de Chile: Oficina Internacional del Trabajo

Lee, D. (1999). Wage Inequality in the United States during the 1980s: Rising Dispersion or Falling Minimum Wage?, Quarterly Journal of Economics, vol. 114 (issue 3), pp. 977-1023.

Lemos, S. (2009). Minimum wage effects in a developing country, Labour Economics, vol 16, (issue 2), pp. $224-237$.

Lustig N., L. Lopez-Calva y E. Ortiz-Juarez (2013). Declining inequality in Latin America in the 2000s: the cases of Argentina, Brazil, and Mexico. World Development, 44, 129-141.

Machin S. y A. Manning (1994). Minimum Wages, Wage Dispersion and Employment: Evidence from the UK Wages Councils, Industrial and Labor Relations Review 47, 319-29.

Manning, A. (2003). Monopsony in Motion: imperfect competition in labor markets, Princeton University Press.

Marinakis A., y J. Velasco (2006). ¿Para qué sirve el salario mínimo?: elementos para su determinación en los países del Cono Sur. Oficina Internacional del Trabajo.

Mauricio, R. (2008). Políticas de transferencias monetarias en Argentina: Una evaluación de su impacto sobre la pobreza y la desigualdad y de sus costos. Documento de trabajo, OIT.

Maurizio, R. (2014a). El impacto distributivo del salario mínimo en la Argentina, el Brasil, Chile y el Uruguay. Serie Políticas Sociales CEPAL ISSN 1564-4162.

Maurizio, R. (2014b). Labour formalization and declining inequality in Argentina and Brazil in 2000s: a dynamic approach, ILO Research Paper (9).

Mirando, J. (2013). "Labor demand stability and the minimum wage e ect on employment: the Chilean evidence". MPRA Paper 46637, University Library of Munich, Germany.

Neri M., G. Gonzaga y J. Camargo (2000). Efeitos informais do salario mínimo e pobreza, Texto Para Discussao $N^{\circ} 724$, IPEA, Rio de Janeiro.

Neumark D. y W. Wascher (1995). The Effect of New Jersey's Minimum Wage Increase on FastFood Employment: A Re-evaluation Using Payroll Records, East Lansing: Michigan State University.

Ronconi, J. (2013). Union Negotiation and Wage Inequality in Argentina: An Empirical Analysis of Recent Trends, CEDLAS Working Paper N. 145, CEDLAS, UNLP.

Trujillo L. y S. Villafañe (2011). Dinámica Distributiva y Políticas Públicas: dos décadas de contrastes en la Argentina Contemporánea, en Novick, M. y Villafañe S. (eds) Distribución del Ingreso. Enfoques y políticas públicas desde el sur, MTESSUNDP, Buenos Aires. 


\section{A. Apéndice}

Tabla A.1. Evolución del salario mensual (en \$) y de la relación entre salario mínimo mensual respecto de la estructura de remuneraciones (en \%) del total de asalariados, asalariados registrados, y asalariados no registrados $1993-2002$

\begin{tabular}{|c|c|c|c|c|c|c|}
\hline \multirow[b]{2}{*}{ Año } & \multicolumn{2}{|c|}{ Asalariados } & \multicolumn{2}{|c|}{ Asalariados formales } & \multicolumn{2}{|c|}{ Asalariados informales } \\
\hline & $\$$ & $\begin{array}{l}\text { SM/salario } \\
\text { promedio }\end{array}$ & $\$$ & $\begin{array}{l}\text { SM/salario } \\
\text { promedio }\end{array}$ & $\$$ & $\begin{array}{c}\text { SM/salario } \\
\text { promedio }\end{array}$ \\
\hline 1993 & 660 & $30.3 \%$ & 743 & $26.9 \%$ & 495 & $40.4 \%$ \\
\hline 1994 & 691 & $28.9 \%$ & 778 & $25.7 \%$ & 469 & $42.7 \%$ \\
\hline 1995 & 698 & $28.7 \%$ & 767 & $26.1 \%$ & 439 & $45.5 \%$ \\
\hline 1996 & 678 & $29.5 \%$ & 759 & $26.3 \%$ & 446 & $44.9 \%$ \\
\hline 1997 & 677 & $29.5 \%$ & 777 & $25.7 \%$ & 429 & $46.6 \%$ \\
\hline $1998^{1}$ & 720 & $27.8 \%$ & 830 & $24.1 \%$ & 443 & $45.2 \%$ \\
\hline $1998^{2}$ & 681 & $29.4 \%$ & 794 & $25.2 \%$ & 414 & $48.3 \%$ \\
\hline 1999 & 636 & $31.4 \%$ & 766 & $26.1 \%$ & 392 & $51.0 \%$ \\
\hline 2000 & 619 & $32.3 \%$ & 764 & $26.2 \%$ & 388 & $51.5 \%$ \\
\hline 2001 & 590 & $33.9 \%$ & 755 & $26.5 \%$ & 353 & $56.7 \%$ \\
\hline 2002 & 551 & $36.3 \%$ & 749 & $26.7 \%$ & 307 & $65.2 \%$ \\
\hline
\end{tabular}

Fuente: SEDLAC (CEDLAS y BANCO MUNDIAL)

Nota: En el año 1998 se produjo un cambio en la EPH, aumentando el número de ciudades relevadas a 28 (hasta ese momento se relevaban 15). Los valores de salario presentados en $1998^{1}$ surgen de considerar sólo las 15 ciudades relevadas hasta 1997, de manera de que los valores sean comparables a los años anteriores. Por su parte los valores presentados en $1998^{2}$ corresponden al ingreso promedio de las 28 ciudades.

Tabla A.2. Asalariados sujetos al SMVM según tramos (en porcentajes)

\begin{tabular}{|c|c|c|c|c|c|c|c|c|}
\hline \multirow[b]{2}{*}{$\begin{array}{l}\text { onda } \\
\text { EPH }\end{array}$} & \multicolumn{4}{|c|}{ registrados por tramos de smvm } & \multicolumn{4}{|c|}{ no registrados por tramos de smvm } \\
\hline & $\begin{array}{c}\text { menos } \\
\text { de } 0.5\end{array}$ & $\begin{array}{c}\text { más de } \\
0.5 y \\
\text { menos } \\
\text { de } 1.0\end{array}$ & $\begin{array}{c}\text { más de } \\
1.0 y \\
\text { menos } \\
\text { de1.5 }\end{array}$ & $\begin{array}{l}\text { más de } \\
1.5 y \\
\text { menos } \\
\text { de } 2\end{array}$ & $\begin{array}{c}\text { menos } \\
\text { de } 0.5\end{array}$ & $\begin{array}{c}\text { más de } \\
0.5 y \\
\text { menos } \\
\text { de } 1.0\end{array}$ & $\begin{array}{c}\text { más de } \\
1.0 \mathrm{y} \\
\text { menos } \\
\text { de } 1.5\end{array}$ & $\begin{array}{c}\text { más de } \\
1.5 y \\
\text { menos } \\
\text { de } 2\end{array}$ \\
\hline 1986 & 0.3 & 1.9 & 11.6 & 22.3 & 2.4 & 13.3 & 25.6 & 26.6 \\
\hline 1988 & 0.2 & 6.4 & 18.9 & 24.5 & 3.7 & 26.8 & 27.7 & 19.9 \\
\hline 1990 & 0.2 & 2.7 & 12.2 & 20.2 & 2.9 & 14.6 & 24.9 & 20.3 \\
\hline 1993 & 0.0 & 0.0 & 0.3 & 0.1 & 0.2 & 1.1 & 0.3 & 2.5 \\
\hline 1995 & 0.0 & 0.6 & 6.4 & 15.4 & 0.9 & 9.9 & 14.0 & 21.5 \\
\hline 1997 & 0.1 & 0.7 & 6.2 & 15.4 & 0.9 & 10.6 & 16.9 & 21.6 \\
\hline 1999 & 0.0 & 0.7 & 5.5 & 14.8 & 1.7 & 9.4 & 16.3 & 23.3 \\
\hline 2001 & 0.2 & 0.9 & 6.5 & 15.5 & 1.1 & 12.4 & 15.0 & 25.5 \\
\hline $\begin{array}{l}2003 \\
\text { Primer }\end{array}$ & 0.2 & 3.9 & 16.4 & 28.1 & 4.6 & 25.4 & 31.5 & 21.6 \\
\hline $\begin{array}{l}\text { semestr } \\
2004\end{array}$ & 0.1 & 3.5 & 15.3 & 27.6 & 6.6 & 22.8 & 33.0 & 37.0 \\
\hline
\end{tabular}

Fuente: Kostzer, D. (2006). Argentina: La recuperación del salario mínimo como herramienta de política de ingresos. En Marinakis, A. y Velasco, J.J. (Eds.): ¿Para qué sirve el salario mínimo? Elementos para su determinación en los países del Cono Sur, pp. 35-104. Santiago de Chile: Oficina Internacional del Trabajo. 
Tabla A.3. Salario mínimo y percentil 80

2003- 2013 -en porcentajes-

\begin{tabular}{cccc}
\hline & $\begin{array}{c}\text { Total } \\
\text { asalariados }\end{array}$ & $\begin{array}{c}\text { Asalariados } \\
\text { formales }\end{array}$ & $\begin{array}{c}\text { Asalariados } \\
\text { informales }\end{array}$ \\
\hline 2003 & 23.6 & 21.0 & 34.7 \\
2004 & 35.0 & 31.9 & 51.3 \\
2005 & 41.4 & 36.2 & 60.6 \\
2006 & 42.0 & 36.1 & 67.8 \\
2007 & 39.4 & 36.3 & 61.4 \\
2008 & 40.2 & 36.3 & 61.9 \\
2009 & 39.8 & 38.1 & 63.8 \\
2010 & 37.7 & 35.4 & 59.5 \\
2011 & 38.1 & 36.3 & 61.2 \\
2012 & 36.9 & 35.7 & 57.1 \\
2013 & 35.1 & 33.6 & 56.1 \\
\hline
\end{tabular}

Fuente: Consejo Nacional de Empleo, la Productividad, y el Salario Mínimo, Vital y Móvil e INDEC.

Nota: En la tabla se presentan los valores de la relación (en \%) entre el salario mínimo y los ingresos del percentil 80 utilizando información del 4to trimestre de la EPHC. 
Tabla A.4. Impacto del Salario Mínimo en las brechas salariales para el total de asalariados. Estimaciones por MCO

\begin{tabular}{|c|c|c|c|c|}
\hline & [1] & [2] & [3] & [4] \\
\hline \multirow[t]{2}{*}{ p10-p80 } & $0.678 * * *$ & $0.708 * * *$ & $0.716^{* * *}$ & $0.718^{* * *}$ \\
\hline & [0.079] & [0.088] & {$[0.078]$} & [0.081] \\
\hline \multirow[t]{2}{*}{ p20-p80 } & $0.690 * * *$ & $0.737 * * *$ & $0.736 * * *$ & $0.740 * * *$ \\
\hline & {$[0.063]$} & {$[0.072]$} & {$[0.070]$} & {$[0.071]$} \\
\hline \multirow[t]{2}{*}{ p30-p80 } & $0.638 * * *$ & $0.679 * * *$ & $0.694 * * *$ & $0.702 * * *$ \\
\hline & [0.048] & [0.054] & [0.052] & [0.053] \\
\hline \multirow[t]{2}{*}{ p40-p80 } & $0.608 * * *$ & $0.637 * * *$ & $0.653 * * *$ & $0.659 * * *$ \\
\hline & [0.048] & [0.057] & [0.052] & {$[0.053]$} \\
\hline \multirow{2}{*}{ p50-p80 } & $0.545^{* * *}$ & $0.580 * * *$ & $0.597^{* * *}$ & $0.602 * * *$ \\
\hline & {$[0.045]$} & {$[0.050]$} & {$[0.048]$} & {$[0.050]$} \\
\hline \multirow[t]{2}{*}{ p60-p80 } & $0.506^{* * *}$ & $0.536 * * *$ & $0.548 * * *$ & $0.552 * * *$ \\
\hline & [0.041] & [0.047] & [0.043] & {$[0.045]$} \\
\hline \multirow[t]{2}{*}{ p70-p80 } & $0.356 * * *$ & $0.382 * * *$ & $0.396 * * *$ & $0.400 * * *$ \\
\hline & [0.038] & [0.043] & [0.042] & [0.043] \\
\hline \multirow{2}{*}{ p90-p80 } & $0.200 * * *$ & $0.239 * * *$ & $0.242 * * *$ & $0.244 * * *$ \\
\hline & [0.039] & [0.033] & [0.034] & [0.034] \\
\hline $\begin{array}{l}\text { Controles } \\
\text { demográficos }\end{array}$ & NO & $\mathrm{SI}$ & $\mathrm{SI}$ & SI \\
\hline $\begin{array}{l}\text { Controles } \\
\text { laborales }\end{array}$ & NO & NO & $\mathrm{SI}$ & $\mathrm{SI}$ \\
\hline $\begin{array}{l}\text { Control x plan } \\
\text { de empleo }\end{array}$ & NO & NO & NO & SI \\
\hline Observaciones & 1044 & 1044 & 1044 & 1044 \\
\hline
\end{tabular}

Nota: Cada entrada en la tabla se refiere al coeficiente de la regresión de las brechas sucesivas de cada decil respecto al ingreso del decil 8 en el salario mínimo efectivo. ${ }^{* * *} p<0.01, * * p<0.05, * p<0.1$; errores estándar entre corchetes, con clústers por aglomerado. En todas las especificaciones se incluyen efectos fijos por período (trimestre-año) y aglomerado. Controles demográficos: edad promedio, años de educación promedio, porcentaje de hombres y tasa de formalidad. Controles laborales: porcentaje de individuos por sector de actividad, porcentaje de trabajadores en el sector público y la tasa de ocupación. Control x plan de empleo: proporción de individuos recibiendo planes de empleo. Los controles demográficos y el porcentaje de individuos por sector de actividad se calcularon por aglomerado para los asalariados a tiempo completo, con ingresos positivos, de entre 16 y 60-65 años para las mujeres y hombres, respectivamente, excluidos los trabajadores del servicio doméstico, así como los beneficiarios de planes de empleo. El resto de los controles se calculó por período y aglomerado para la población entre 16 y 60-65 años, para las mujeres y hombres, respectivamente. 
Tabla A.5. Impacto del Salario Mínimo en las brechas salariales para los asalariados formales Estimaciones por MCO

\begin{tabular}{|c|c|c|c|c|}
\hline & [1] & [2] & [3] & [4] \\
\hline \multirow[t]{2}{*}{ p10-p80 } & $0.784 * * *$ & $0.779 * * *$ & $0.800 * * *$ & $0.801 * * *$ \\
\hline & {$[0.072]$} & {$[0.078]$} & {$[0.068]$} & {$[0.071]$} \\
\hline \multirow[t]{2}{*}{ p20-p80 } & $0.741 * * *$ & $0.741 * * *$ & $0.757^{* * *}$ & $0.754 * * *$ \\
\hline & {$[0.058]$} & {$[0.063]$} & {$[0.056]$} & {$[0.057]$} \\
\hline \multirow[t]{2}{*}{ p30-p80 } & $0.710 * * *$ & $0.714 * * *$ & $0.735 * * *$ & $0.736 * * *$ \\
\hline & {$[0.055]$} & [0.058] & [0.048] & {$[0.050]$} \\
\hline \multirow[t]{2}{*}{ p40-p80 } & $0.651 * * *$ & $0.659 * * *$ & $0.677^{* * *}$ & $0.678 * * *$ \\
\hline & [0.044] & {$[0.047]$} & {$[0.041]$} & {$[0.043]$} \\
\hline \multirow[t]{2}{*}{ p50-p80 } & $0.607^{* * *}$ & $0.615^{* * *}$ & $0.632 * * *$ & $0.633^{* * *}$ \\
\hline & {$[0.043]$} & {$[0.046]$} & {$[0.039]$} & {$[0.040]$} \\
\hline \multirow[t]{2}{*}{ p60-p80 } & $0.509 * * *$ & $0.520 * * *$ & $0.534 * * *$ & $0.535^{* * *}$ \\
\hline & {$[0.033]$} & [0.037] & [0.036] & {$[0.036]$} \\
\hline \multirow[t]{2}{*}{ p70-p80 } & $0.360 * * *$ & $0.376^{* * *}$ & $0.391 * * *$ & $0.394 * * *$ \\
\hline & {$[0.036]$} & [0.038] & [0.034] & {$[0.035]$} \\
\hline \multirow{2}{*}{ p90-p80 } & $0.229 * * *$ & $0.257 * * *$ & $0.263^{* * *}$ & $0.261 * * *$ \\
\hline & {$[0.044]$} & {$[0.043]$} & {$[0.044]$} & {$[0.044]$} \\
\hline $\begin{array}{l}\text { Controles } \\
\text { demográficos }\end{array}$ & NO & SI & $\mathrm{SI}$ & $\mathrm{SI}$ \\
\hline $\begin{array}{l}\text { Controles } \\
\text { laborales }\end{array}$ & NO & NO & $\mathrm{SI}$ & $\mathrm{SI}$ \\
\hline $\begin{array}{l}\text { Control x plan } \\
\text { de empleo }\end{array}$ & NO & NO & NO & $\mathrm{SI}$ \\
\hline Observaciones & 1044 & 1044 & 1044 & 1044 \\
\hline
\end{tabular}

Nota: Cada entrada en la tabla se refiere al coeficiente de la regresión de las brechas sucesivas de cada decil respecto al ingreso del decil 8 en el salario mínimo efectivo. ${ }^{* * *} p<0.01, * * p<0.05, * p<0.1$; errores estándar entre corchetes, con clústers por aglomerado. En todas las especificaciones se incluyen efectos fijos por período (trimestre-año) y aglomerado. Controles demográficos: edad promedio, años de educación promedio y porcentaje de hombres. Controles laborales: porcentaje de individuos por sector de actividad, porcentaje de trabajadores en el sector público y la tasa de ocupación. Control x plan de empleo: proporción de individuos recibiendo planes de empleo. Los controles demográficos y el porcentaje de individuos por sector de actividad se calcularon por aglomerado para los asalariados a tiempo completo, con ingresos positivos, de entre 16 y 60-65 años para las mujeres y hombres, respectivamente, excluidos los trabajadores del servicio doméstico, así como los beneficiarios de planes de empleo. El resto de los controles se calculó por período y aglomerado para la población entre 16 y 60-65 años, para las mujeres y hombres, respectivamente. 
Tabla A.6. Impacto del Salario Mínimo en las brechas salariales para los asalariados informales Estimaciones por MCO

\begin{tabular}{|c|c|c|c|c|}
\hline & [1] & [2] & [3] & [4] \\
\hline \multirow[t]{2}{*}{ p10-p80 } & $0.644 * * *$ & $0.635 * * *$ & $0.634 * * *$ & $0.630 * * *$ \\
\hline & [0.061] & {$[0.063]$} & [0.058] & [0.057] \\
\hline \multirow[t]{2}{*}{ p20-p80 } & $0.625^{* * *}$ & $0.619 * * *$ & $0.618^{* * *}$ & $0.621 * * *$ \\
\hline & [0.047] & [0.046] & [0.045] & [0.046] \\
\hline \multirow[t]{2}{*}{ p30-p80 } & $0.584 * * *$ & $0.578 * * *$ & $0.579 * * *$ & $0.582 * * *$ \\
\hline & [0.042] & [0.042] & [0.041] & {$[0.040]$} \\
\hline \multirow[t]{2}{*}{ p40-p80 } & $0.580 * * *$ & $0.573 * * *$ & $0.577^{* * *}$ & $0.576 * * *$ \\
\hline & [0.039] & [0.039] & [0.038] & [0.037] \\
\hline \multirow[t]{2}{*}{ p50-p80 } & $0.560 * * *$ & $0.556 * * *$ & $0.556 * * *$ & $0.559 * * *$ \\
\hline & [0.037] & [0.038] & [0.036] & {$[0.036]$} \\
\hline \multirow[t]{2}{*}{ p60-p80 } & $0.430 * * *$ & $0.429 * * *$ & $0.431 * * *$ & $0.433^{* * *}$ \\
\hline & [0.035] & [0.037] & [0.037] & [0.036] \\
\hline \multirow[t]{2}{*}{ p70-p80 } & $0.366^{* * *}$ & $0.364 * * *$ & $0.365^{* * *}$ & $0.367 * * *$ \\
\hline & [0.025] & {$[0.026]$} & [0.026] & [0.026] \\
\hline \multirow[t]{2}{*}{ p90-p80 } & $0.193 * * *$ & $0.201 * * *$ & $0.199 * * *$ & $0.202 * * *$ \\
\hline & [0.033] & [0.035] & [0.035] & [0.035] \\
\hline $\begin{array}{l}\text { Controles } \\
\text { demográficos }\end{array}$ & NO & SI & $\mathrm{SI}$ & SI \\
\hline $\begin{array}{l}\text { Controles } \\
\text { laborales }\end{array}$ & NO & NO & $\mathrm{SI}$ & SI \\
\hline $\begin{array}{l}\text { Control x plan } \\
\text { de empleo }\end{array}$ & NO & NO & NO & SI \\
\hline Observaciones & 1044 & 1044 & 1044 & 1044 \\
\hline
\end{tabular}

Nota: Cada entrada en la tabla se refiere al coeficiente de la regresión de las brechas sucesivas de cada decil respecto al ingreso del decil 8 en el salario mínimo efectivo. ${ }^{* *} p<0.01,{ }^{*} p<0.05, * p<0.1$; errores estándar entre corchetes, con clústers por aglomerado. En todas las especificaciones se incluyen efectos fijos por período (trimestre-año) y aglomerado. Controles demográficos: edad promedio, años de educación promedio y porcentaje de hombres. Controles laborales: porcentaje de individuos por sector de actividad, porcentaje de trabajadores en el sector público y la tasa de ocupación. Control x plan de empleo: proporción de individuos recibiendo planes de empleo. Los controles demográficos y el porcentaje de individuos por sector de actividad se calcularon por aglomerado para los asalariados a tiempo completo, con ingresos positivos, de entre 16 y 60-65 años para las mujeres y hombres, respectivamente, excluidos los trabajadores del servicio doméstico, así como los beneficiarios de planes de empleo. El resto de los controles se calculó por período y aglomerado para la población entre 16 y 60-65 años, para las mujeres y hombres, respectivamente. 
Gráfico A.1: Operatividad del salario mínimo por año y aglomerado Asalariados formales

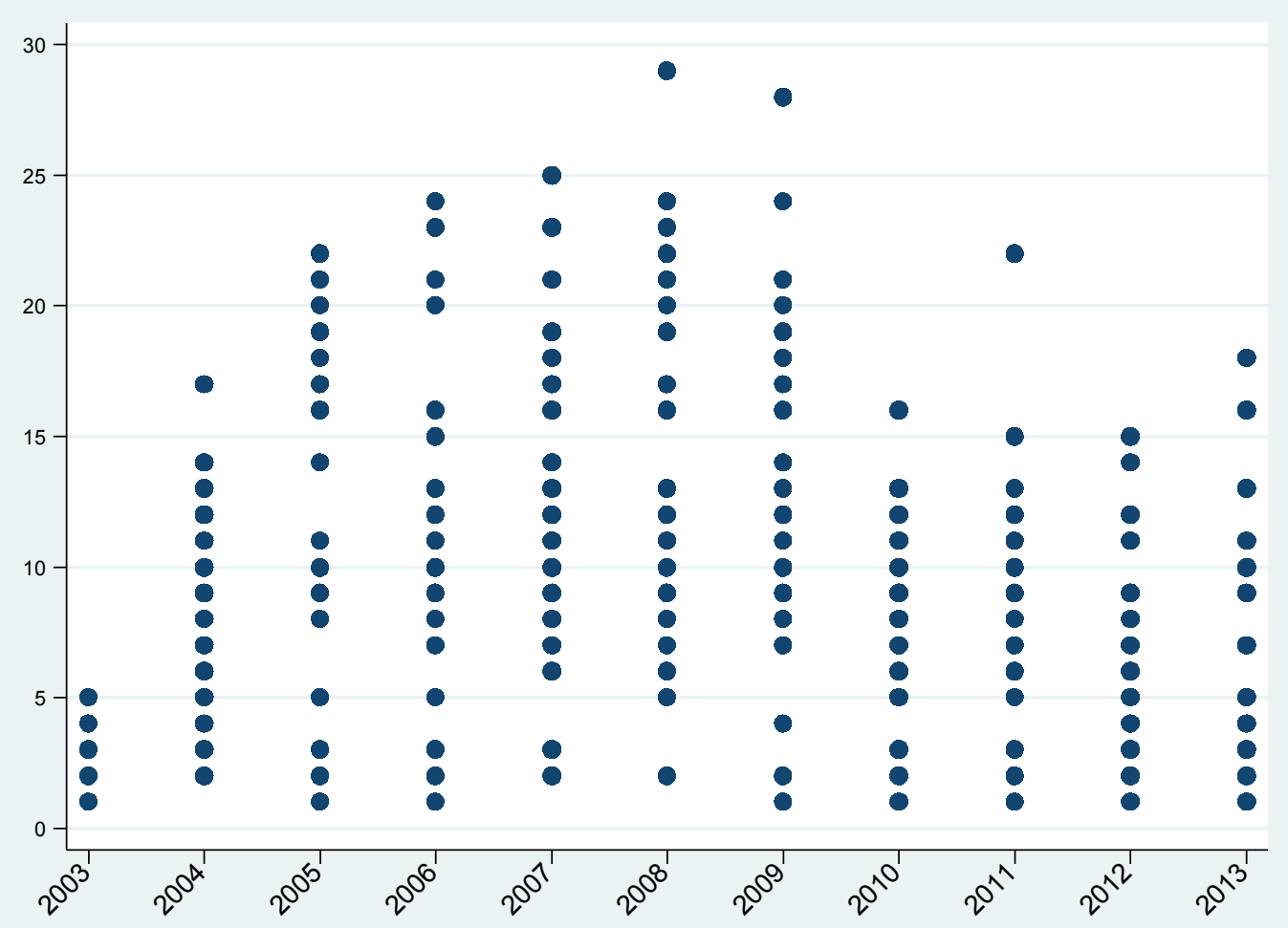

Fuente: Consejo Nacional de Empleo, la Productividad, y el Salario Mínimo, Vital y Móvil e INDEC:

Nota: Cada observación corresponde a un aglomerado y representa la operatividad del salario mínimo entendida como el percentil del ingreso a partir del cual los asalariados formales obtienen remuneraciones superiores al salario mínimo nominal, utilizando información del 4to trimestre de la EPHC. 